\title{
Review
}

\section{Nutrition, atherosclerosis, arterial imaging, cardiovascular risk stratification, and manifestations in COVID-19 framework: a narrative review}

\author{
Smiksha Munjral ${ }^{1}$, Puneet Ahluwalia ${ }^{2}$, Ankush D. Jamthikar ${ }^{1,3}$, Anudeep Puvvula ${ }^{1,4}$, Luca Saba ${ }^{5}$, \\ Gavino Faa ${ }^{6}$, Inder M Singh ${ }^{1}$, Paramjit S. Chadha ${ }^{1}$, Monika Turk ${ }^{7}$, Amer M. Johri ${ }^{8}$, \\ Narendra N Khanna ${ }^{9}$, Klaudija Viskovic ${ }^{10}$, Sophie Mavrogeni ${ }^{11}$, John R Laird ${ }^{12}$, Gyan Pareek ${ }^{13}$, \\ Martin Miner ${ }^{14}$, David W. Sobel ${ }^{13}$, Antonella Balestrieri ${ }^{5}$, Petros P Sfikakis ${ }^{15}$, George Tsoulfas $^{16}$, \\ Athanasios Protogerou ${ }^{17}$, Prasanna Misra ${ }^{18}$, Vikas Agarwal ${ }^{18}$, George D. Kitas ${ }^{19,20}$, Raghu Kolluri ${ }^{21}$, \\ Jagjit Teji $^{22}$, Mustafa Al-Maini ${ }^{23}$, Surinder K. Dhanjil ${ }^{1}$, Meyypan Sockalingam ${ }^{24}$, Ajit Saxena ${ }^{9}$, \\ Aditya Sharma $^{25}$, Vijay Rathore ${ }^{26}$, Mostafa Fatemi ${ }^{27}$, Azra Alizad ${ }^{28}$, Vijay Viswanathan ${ }^{29}$, \\ P K Krishnan ${ }^{30}$, Tomaz Omerzu ${ }^{31}$, Subbaram Naidu ${ }^{32}$, Andrew Nicolaides ${ }^{33}$, Jasjit S. Suri ${ }^{1, *}$
}

${ }^{1}$ Stroke Monitoring and Diagnostic Division, AtheroPoint ${ }^{T M}$, Roseville, CA 95678, USA, ${ }^{2}$ Max Institute of Cancer Care, Max Superspeciality Hospital, 110058 New Delhi, India, ${ }^{3}$ Visvesvaraya National Institute of Technology, 440001 Nagpur, India, ${ }^{4}$ Annu's Hospitals for Skin and Diabetes, 24002 Nellore, AP, India, ${ }^{5}$ Department of Radiology, Azienda Ospedaliero Universitaria, 09125 Cagliari, Italy, ${ }^{6}$ Department of Pathology, AOU of Cagliari, 09125 Cagliari, Italy, ${ }^{7}$ The Hanse-Wissenschaftskolleg Institute for Advanced Study, 27749 Delmenhorst, Germany, ${ }^{8}$ Department of Medicine, Division of Cardiology, Queen's University, Kingston, ON K7L, Canada, ${ }^{9}$ Department of Cardiology, Indraprastha APOLLO Hospitals, 110001 New Delhi, India, ${ }^{10}$ University Hospital for Infectious Diseases, 10000 Zagreb, Crotia, ${ }^{11}$ Cardiology Clinic, Onassis Cardiac Surgery Center, 10671 Athens, Greece, ${ }^{12}$ Heart and Vascular Institute, Adventist Health St. Helena, St Helena, CA 94574, USA, ${ }^{13}$ Minimally Invasive Urology Institute, Brown University, Providence, RI 02906, USA, ${ }^{14}$ Men's Health Center, Miriam Hospital Providence, RI 02903, USA, ${ }^{15}$ Rheumatology Unit, National Kapodistrian University of Athens, 10671 Athens, Greece, ${ }^{16}$ Aristoteleion University of Thessaloniki, 54630 Thessaloniki, Greece, ${ }^{17}$ National \& Kapodistrian University of Athens, 10671 Athens, Greece, ${ }^{18}$ Sanjay Gandhi Postgraduate Institute of Medical Sciences, 226018 Lucknow, UP, India, ${ }^{19}$ Academic Affairs, Dudley Group NHS Foundation Trust, DY2 8 Dudley, UK, ${ }^{20}$ Arthritis Research UK Epidemiology Unit, Manchester University, M13 9 Manchester, UK, ${ }^{21}$ OhioHealth Heart and Vascular, OH 43311, USA, ${ }^{22}$ Ann and Robert H. Lurie Children's Hospital of Chicago, Chicago, IL 60629, USA, ${ }^{23}$ Allergy, Clinical Immunology and Rheumatology Institute, Toronto, ON M5H, Canada, ${ }^{24}$ MV Center of Diabetes, 600003 Bangalore, India, ${ }^{25}$ Division of Cardiovascular Medicine, University of Virginia, Charlottesville, VA 22903, USA, ${ }^{26}$ Nephrology Department, Kaiser Permanente, Sacramento, CA 95823, USA, ${ }^{27}$ Department of Physiology \& Biomedical Engg., Mayo Clinic College of Medicine and Science, MN 55441, USA, ${ }^{28}$ Department of Radiology, Mayo Clinic College of Medicine and Science, MN 55441, USA, ${ }^{29}$ MV Hospital for Diabetes and Professor MVD Research Centre, 600003 Chennai, India, ${ }^{30}$ Neurology Department, Fortis Hospital, 562123 Bangalore, India, ${ }^{31}$ Department of Neurology, University Medical Centre Maribor, 2000 Maribor, Slovenia, ${ }^{32}$ Electrical Engineering Department, University of Minnesota, Duluth, MN 55812, USA, ${ }^{33}$ Vascular Screening and Diagnostic Centre, University of Nicosia Medical School, 999058 Nicosia, Cyprus

\section{Abstract}

Background: Atherosclerosis is the primary cause of the cardiovascular disease (CVD). Several risk factors lead to atherosclerosis, and altered nutrition is one among those. Nutrition has been ignored quite often in the process of CVD risk assessment. Altered nutrition along with carotid ultrasound imaging-driven atherosclerotic plaque features can help in understanding and banishing the problems associated with the late diagnosis of CVD. Artificial intelligence (AI) is another promisingly adopted technology for CVD risk assessment and management. Therefore, we hypothesize that the risk of atheroscle- rotic CVD can be accurately monitored using carotid ultrasound imaging, predicted using AI-based algorithms, and reduced with the help of proper nutrition. Layout: The review presents a pathophysiological link between nutrition and atherosclerosis by gaining a deep insight into the processes involved at each stage of plaque development. After targeting the causes and finding out results by lowcost, user-friendly, ultrasound-based arterial imaging, it is important to (i) stratify the risks and (ii) monitor them by measuring plaque burden and computing risk score as part of the preventive framework. Artificial intelligence (AI)based strategies are used to provide efficient CVD risk as- 


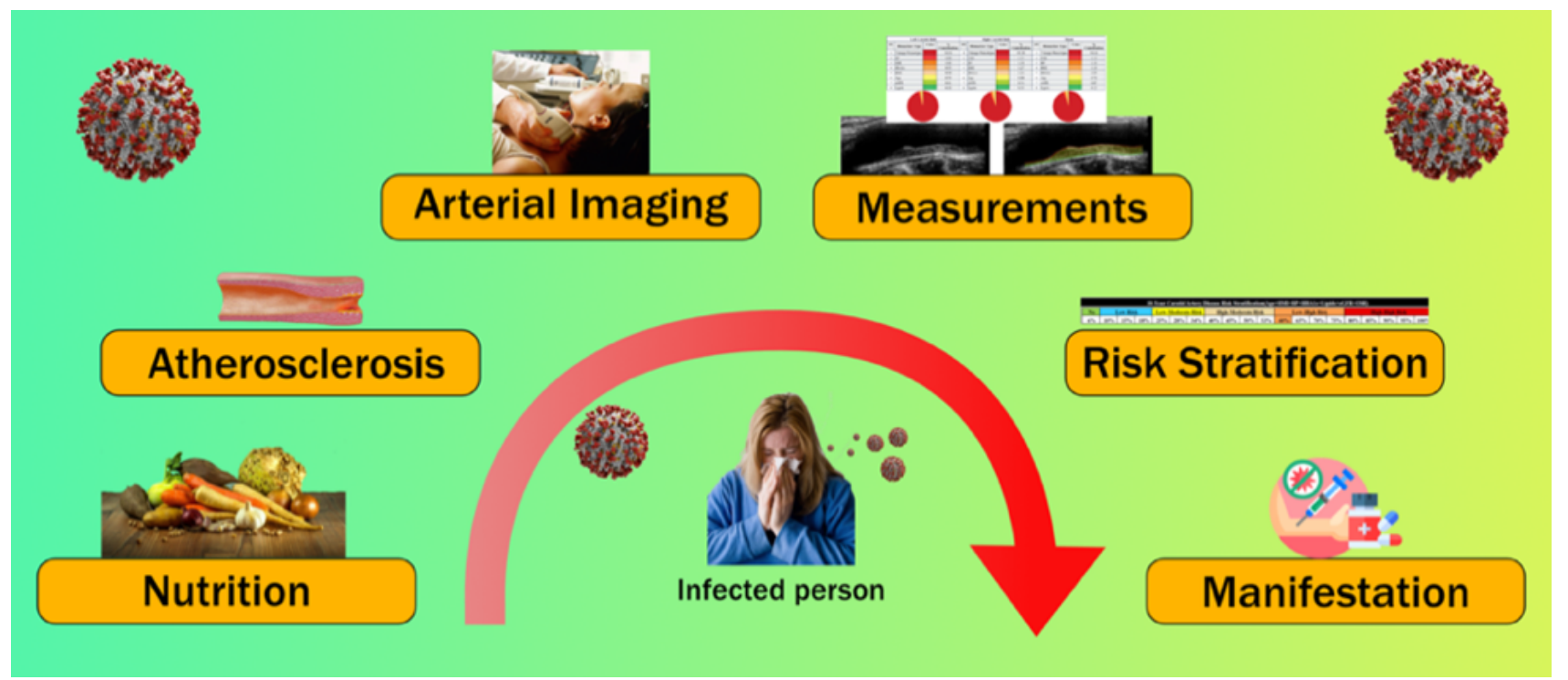

Fig. 1. Global view and CVD stages for risk assessment.

sessments. Finally, the review presents the role of AI for CVD risk assessment during COVID-19. Conclusions: By studying the mechanism of low-density lipoprotein formation, saturated and trans fat, and other dietary components that lead to plaque formation, we demonstrate the use of CVD risk assessment due to nutrition and atherosclerosis disease formation during normal and COVID times. Further, nutrition if included, as a part of the associated risk factors can benefit from atherosclerotic disease progression and its management using AI-based CVD risk assessment.

\section{Introduction}

Cardiovascular diseases (CVD) are a major cause of mortality and morbidity in the world. According to World Health Organization (WHO), globally, every year, 17.7 million people die due to CVD [1]. Atherosclerosis is the primary cause of CVD [2-4], and plaque rupture. It is responsible for almost $70 \%$ of fatal cardiovascular events (CVE) [5]. There are several risk factors responsible for atherosclerotic disease, but the prolonged exposure to hyperglycemia and insulin resistance, clustered with other risk factors such as obesity, arterial hypertension, and dyslipidemia constitutes an important stimulus in plaque development and progression [6-8]. It is therefore important to look into unhealthy lifestyles that lead to CVD [9, 10]. A sedentary lifestyle, a decrease in physical demands during the job workflow, and increased availability of affordable, palatable, high-calorie foods have fueled the epidemic of obesity [11-13]. Obesity is a modifiable risk factor for atherosclerosis [14-17], and its prevalence in childhood is seen to have adverse effects on cardiovascular health [18].

Dietary and nutritional risks are responsible for $55 \%$ of cardiovascular events in countries with high socio- demographic index (SDI) [19]. In terms of the nutrition paradigm, increasing availability and consumption of processed and pre-packaged foods is associated with a twofold increased risk of atherosclerosis [20-23]. Epidemiological evidence suggests that diets low in saturated fat, with a balanced amount of fruits and vegetables, helps against the progression of atherosclerosis [24, 25]. Nutrition is often ignored in the CVD risk assessment paradigm, mainly due to (a) its appearance in the early CVD risk management pipeline and (b) its categorization in the preventive cardiology framework compared to CVD treatment paradigms [26]. Looking at the impact of nutrition on atherosclerosis and CVD, it is important to consider the effect of nutritional factors on the CVD risk assessment. According to the American Heart Association (AHA) guidelines on the primary prevention of CVD, adults diagnosed with obesity are at an increased risk of CVD, atrial fibrillation, and heart failure [27, 28]. It is therefore recommended for these individuals to have a mindful food intake [29]. Prevention of CVE can be possible by identifying risk factors associated with atherosclerosis. This can be accomplished by screening moderate to high-risk patients who are likely to experience CVE and then recommending an appropriate treatment plan for reversing the effect of atherosclerotic plaque buildup, so-called "plaque regression".

It is well established that conventional calculators such as Framingham risk score (FRS), Systematic Coronary Risk Evaluation (SCORE), and Pooled Cohort Risk Equation by ACC/AHA, are used for estimating the CVD risk [30]. These calculators use conventional risk factors that include office-based and laboratory-based biomarkers to produce results that are age-driven [31]. The INTERHEART [32] and INTERSTROKE [33] studies have shown nearly $90 \%$ of the CVD-related mortalities are associated with such types of conventional cardiovascular risk fac- 
tors. Even though these conventional calculators are popular, they do not integrate image-based phenotypes, that directly reflect plaque vulnerability.

Ultrasound imaging is the most popular lowcost, preventive screening solution, which is currently adopted for CVD/stroke risk assessment [34, 35]. Compared to its other non-invasive counterparts [34], it is a portable and user-friendly imaging technique. For example, AtheroEdge ${ }^{\mathrm{TM}}$ — a carotid image-based CVD risk calculator takes advantage of image phenotypes such as carotid intima-media thickness [36], plaque area, and its variability derived from the carotid scans [31, 35, 37]. Such a tool can be better used in the preventive framework provided that it can be applied to study the effect of nutrition [38-41] (see Fig. 1).

CVD risk assessment becomes even more important in the era of COVID-19 since it has a great deal of impact on underlying conditions, complications of infections, and other diseases [42]. A high incidence of thromboembolic events has been found in patients with COVID-19 [43]. It is also observed that COVID-19 leads to the worsening of conditions in the presence of CVD [44-46]. We will focus on the molecular pathways that can cause epithelial dysfunction and atherosclerotic plaque formation leading to the risk of major cardiovascular events during COVID-19.

Thus the overall objective of this study is to understand how (a) nutrition affects the formation of atherosclerosis and plaque formation, (b) the role of low-cost surrogate CVD such as carotid ultrasound-based screening which can help in effective AI-based risk stratification and monitoring the atherosclerotic disease, (c) manifestations types, and (d) study the effect of COVID-19 on the CVD cycle.

\section{Search strategy}

PRISMA model was adapted for the search strategy (Fig. 2). We used several repositories to retrieve the maximum amount of relevant information as required. PubMed and Google Scholar were used for searching the keywords such as "nutrition and atherosclerosis", "nutrition, atherosclerosis, myocardial infarction", "nutrition stroke atherosclerosis”, "atherosclerosis risk factors”, "nutrition, ethnicity, geographical effects and heart disease”, "nutrition obesity diabetes atherosclerosis", “arterial imaging in atherosclerosis", "atherosclerotic tissue classification and characterization", "plaque tissue characterization", "diet and atherosclerosis", "cardiac injury and COVID-19”, "atherosclerosis and COVID-19”. We found about 332 articles on PubMed and about 17,400 articles on Google scholar. A total of 16,000 studies were identified, and duplicates were removed using the feature called "Find Duplicates" in EndNote software by Clarivate Analytics [47]. After applying advanced filters such as time and relevance, this narrowed down to 600 articles. The three exclusion criterias were (i) studies not related, (ii) non-relevant ar- ticles, and (iii) having insufficient data. This excluded 15,200,200, and 320 studies (marked as E1, E2, and E3), leading to the final selection of 280 studies.

\section{Cardiovascular risk factors}

A person's susceptibility to developing atherosclerosis may be identified by the risk factors associated with it. The risk factors responsible for atherosclerotic disease can be categorized into (a) conventional, such as hypertension, obesity, body mass index, ethnicity, gender, ethanol use, and smoking [48] and (b) blood biomarkers such as lipids, hemoglobin A1c (HbA1c) as diabetes index [35, 49], estimated glomerular filtration rate (eGFR) as renal index [50], erythrocyte sedimentation rate (ESR) as rheumatoid arthritis index [51], homocysteine, triglycerides, and hCRP/c reactive protein. Fig. 3A (Ref. [52]) shows the prevalence of these risk factors in relation to the cause of atherosclerosis and related cardiovascular diseases.

\subsection{Conventional biomarkers as a risk factor}

These risk factors are significantly associated with an increased risk of coronary artery disease. We discuss here several types of risk factors that assist in atherosclerotic lesion formation. Individuals with high blood pressure are more likely to develop atherosclerosis. It has been observed that hypertension causes vascular dysfunction and facilitates the development and progression of atherosclerosis.

This progression is because hypertension oxidatively injures the endothelium leading to the activation of redox-sensitive mechanisms. These mechanisms act in recruiting the mononuclear leukocytes into the wall of the arteries [53]. Another associated risk factor is obesity. It is a known fact that obesity and physical inactivity are some of the leading causes of atherosclerosis. This is due to the influence of many mechanisms such as systemic inflammation, an increase in glucose levels by causing insulin resistance and increasing blood pressures and abnormal lipid profiles [54]. Further, it can be seen that adipokines, a cytokine secreted by adipose tissue, regulate the function of endothelial, arterial smooth muscle, and macrophage cells by directly modulating the atherogenic environment of the vessel wall [55]. Adipose tissue in excess is found in obese patients, and obesity is also seen to have effects on left ventricular remodeling [56]. Further, it is also pointed out that insulin resistance and gallstone disease potentiate each other's effects and might lead to excessive weight gain in the individuals who are prone to be obese [57]. In young adult men with higher BMI, atherosclerotic lesion formation was more frequent and advanced [58].

Several studies on ethanol have been associated with atherosclerosis progression as well as regression. A two-way effect has been observed in high, low/moderate intakes of alcohol consumption. It is argued that even though 


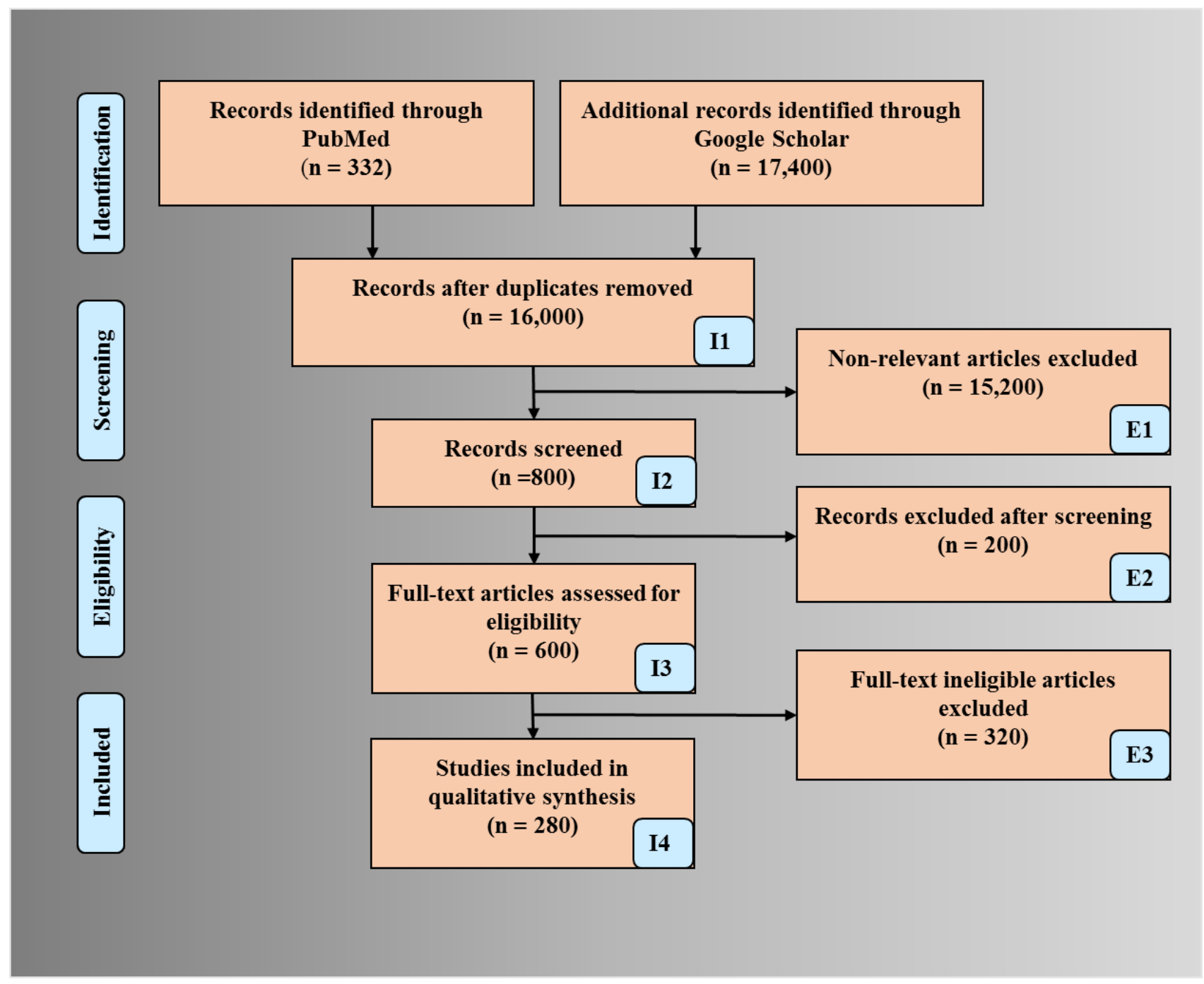

Fig. 2. PRISMA model depicting search strategy.

alcohol consumption may have its benefits, it equally harms if consumed in high amounts. Benefits are seen as it increases HDL, has anti-inflammatory properties, and has thrombolytic functions. However, if consumed in high amounts, it promotes hypercholesterolemia, is proinflammatory, and also leads to hypertension [59, 60]. Not only ethanol intoxication but also smoking is seen to have adverse effects. It has been researched that the toxins in tobacco have a lowering effect on HDL simultaneously raising the levels of LDL [61]. Nicotine and carbon monoxide present in tobacco and smoke are also seen to have adverse effects on plaque buildup as they damage the endothelium [62]. This is because nicotine produces superoxide anions, which in turn reduces the bioavailability of nitric oxide. Further, this increases the production of endothelin that results in endothelial dysfunction [63]. If patients with hypertension are chronic smokers, their risk of developing coronary artery disease is also seen to be high [64].

When discussing unmodifiable conventional risk factors, we can take into account ethnicity and gender. Both ethnicity and gender influence the likelihood of engaging in a healthy lifestyle. It was further observed in a study that black women had higher BMI and ASCVD scores, they were less likely than white women to have reported healthy dietary habits or have themselves engaged in losing weight. In the same study, it was also seen that white men were more likely than Hispanic men to have engaged in healthy eating habits [65]. In another study, progression of atherosclerosis was seen in premenopausal women [66].

\subsection{Blood biomarkers as risk factors}

It is seen that hyperglycemia acts on the vascular tissue at cellular levels and alters it, leading to the acceleration of the formation of atherosclerosis. The main reaction that is often involved in this formation process is referred to as "Maillard or browning reaction" (reaction between reducing D-sugar and amino acid) [67]. In patients with diabetes mellitus, incidental micro and macrocalcification are considered as a biomarker for atherosclerotic burden as depicted in Fig. 3B-D [52]. It is proved that 

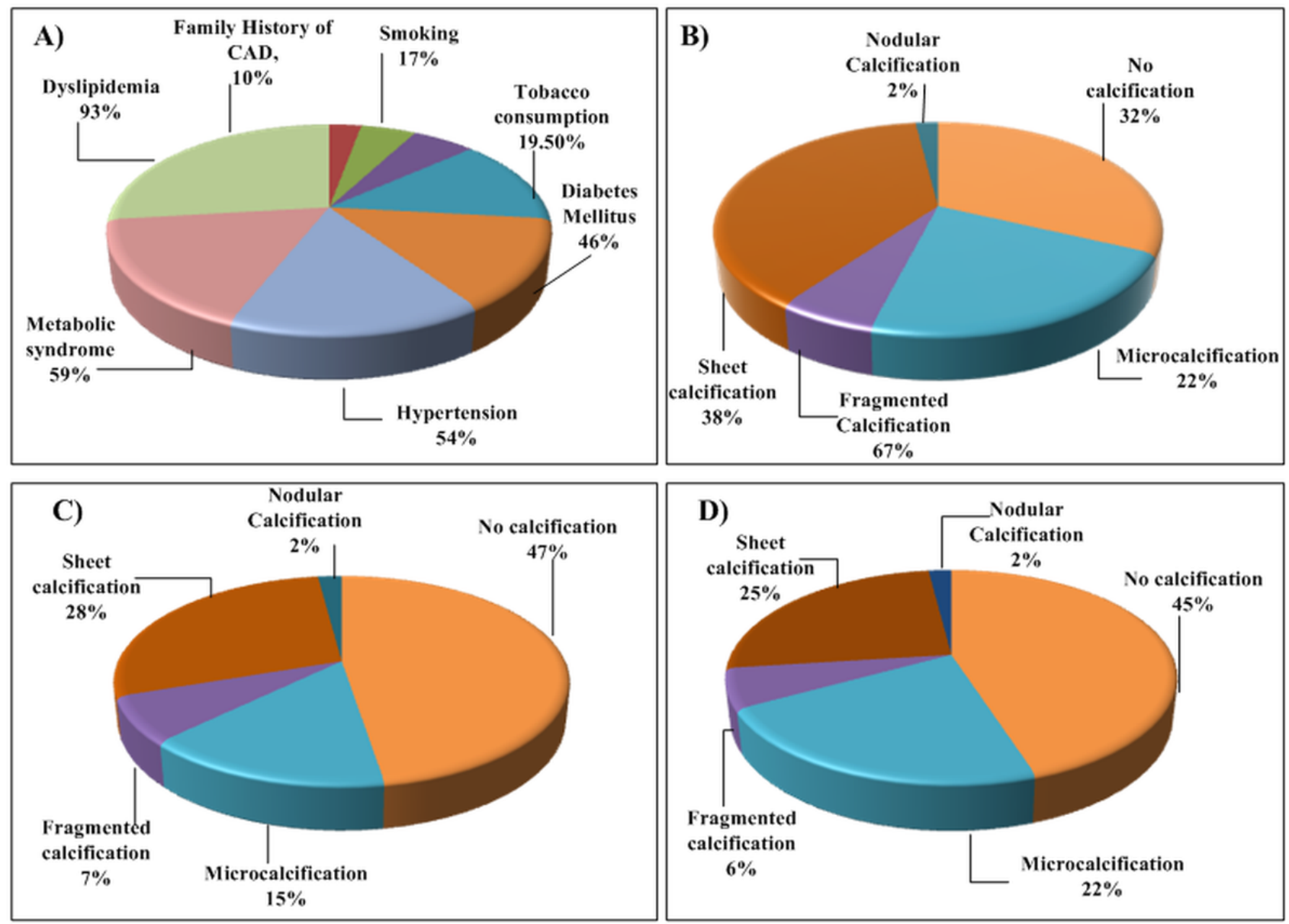

Fig. 3. Statistical distribution on CAD. (A) Risk factors. (B) $\%$ deaths (HbA1c $\geq 12 \%$ ). (C) $\%$ deaths (HbA1c $<8 \%$ ). (D) $\%$ deaths (HbA1c $8 \%$ to $<12 \%)$ [52].

moderate to severe renal impairment has a greater effect on atherosclerosis and its progression [68]. CKD is seen to promote the formation of the foam cells by down regulating cholesterol efflux through activation of nuclear factor and repression of cholesterol transporter. Further, in CKD patients, systemic and macrophage angiotensin 2 is seen to promote atherosclerosis [69]. It is seen that the mechanism of atherosclerosis is driven by rheumatoid arthritis (RA) [70]. Pro-inflammatory cytokines such as TNF- $\alpha$, IL-17, and IL-6 are seen to have pathogenic roles in RA; thus they are prone to lead to premature atherosclerosis.

Type 1 interferon causes vascular damage in systemic lupus erythematosus through pathways that are crucial steps towards atherosclerosis progression [71]. Research suggests that homocysteine is an independent risk factor for atherosclerosis [72]. More than 80 crosssectional, case-control, and cohort studies have linked hyperhomocysteinemia with CHD risk. Triglyceride levels appear to provide unique information as a biomarker of CVD risk. The association of triglyceride levels with apolipoproteins and atherogenic lipoproteins, especially apo C-III, gives unique information as a biomarker for the risk of CVD. Thus hypertriglyceridemia is also a risk fac- tor for atherosclerosis [73]. Similarly, dyslipidemia is an abnormal level of lipid content in the blood. It causes a major risk of developing CVD [74]. Hence, it is important to manage dyslipidemia for the prevention of atherosclerosis and CVD. Research suggests that monomeric $C$ reactive protein is a potential regulator of signaling pathways that are linked to endothelial cell inflammation, thrombosis, and angiogenesis [75]. By exerting pro-inflammatory effects, it contributes to atherosclerosis formation. It is also seen to bind with multiple ligands and is involved in multiple steps of atherosclerosis [76].

\section{Nutrition}

It is a well-established fact that nutrition and variations of food play an important role in the development of atherosclerosis and plaque build-up. Thus, there is a link between nutrition and atherosclerosis, and we will explore that in this section.

Trans fat and saturated fat are seen as the major contributors to plaque formation as they act by increasing the amount of LDL in the body $[9,25]$. Several epidemi- 


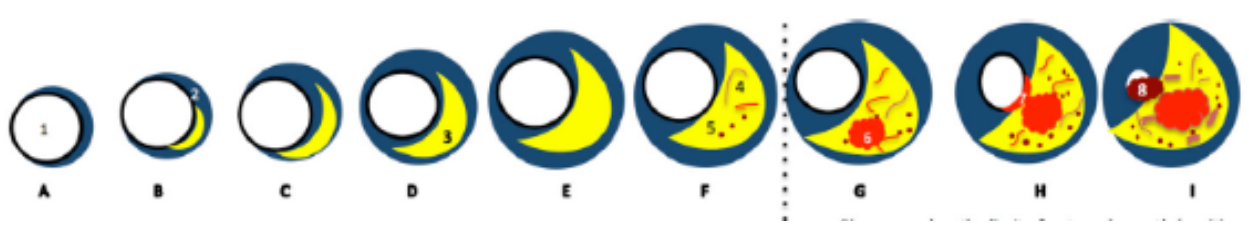

Fig. 4. Plaque progression (Reproduced with permission) [86].

ological studies have been seen to promote trans-fat as a major risk factor for atherosclerosis [77, 78]. Trans fat acts by suppressing TGF- $\beta$, which is thus mediated by increased deposition of cholesterol into the cellular plasma of the vascular tissue [79]. Similarly, saturated fats raise the levels of LDL and total blood cholesterol, which in turn suppress the activity of LDL receptors. High cholesterol is seen to increase LDL synthesis by (a) decreasing LDL catabolism in the cells and (b) increasing the plasma cholesterol.

Lipoproteins are complexes of amphibiatic proteins that are comprised of lipids, proteins, and phospholipids [80]. The ratio of protein to fat determines the density of the protein. Plasma lipoproteins have been grouped into five major classes based on their densities: (i) chylomicrons, which are the transporter of dietary triglyceride, (ii) very-low-density lipoproteins (VLDL), that transports endogenous triglyceride, (iii) intermediate-density lipoproteins (IDL), (iv) low-density lipoproteins (LDL), and (v) high-density lipoproteins (HDL) [81]. It is seen that atherogenic lipoproteins floating in the VLDL-IDL region promote atherosclerosis. These atherogenic lipoproteins may be classified as LDL and lipoprotein remnants. Antiatherogenic lipoproteins like HDL prevent atherosclerosis [82, 83]. Even though low-density lipoproteins are the major contributors to plaque cholesterol, it is seen that chylomicron remnants are also taken up into the subendothelial space [84]. ApoB100 is a form of LDL and is a protein that helps in moving cholesterol around our body. It has a central role in the development of atherosclerosis and plaque formation as seen in Fig. 4 [85]. Plaque may develop over time due to bad nutritional habits or it may be due to familial hypercholesterolemia [87].

Now we shall look at a few nutrients, food groups, and their effect on atherosclerosis. Observations showed that low omega-3 fatty acids intake leads to arrhythmia, which may further cause thrombosis [88]. It also promotes platelet aggregation leading to an increase in fibrous plaque and increased inflammation-causing injury to coronary arteries [89, 90]. Glancing at the foods of animal origin, eggs in specific quantities are considered to be unhealthy for patients suffering from CVD. A recent study reported that consumption of egg yolk regularly should be avoided as it is seen to have increased carotid plaque [91]. As we know that dietary cholesterol itself is harmful and potentiates the effect of saturated fats. Therefore, the egg yolk must be avoided by patients at high risk. The egg may also be associated with the increase of type 2 diabetes mellitus
[92]. Other foods in animal nutrition such as processed and red meat have also been seen to promote CVD risk in patients. This is due to the presence of trimethylamine, phosphatidylcholine, choline, and l-carnitine [93]. It is therefore important to understand this link and see how these foods cause adverse effects on the body.

The pathophysiological link between nutrition and atherosclerosis

Animal dietary products increase the risk of atherosclerosis. Many recent articles show that dysbiosis (impaired microbiota) of intestinal microbes are linked with certain animal dietary products that can generate metabolites (intermediate products) like trimethylamine (TMA) and trimethylamine $\mathrm{N}$-oxide levels (TMAO), which acts as key factors in developing atherosclerosis and results in cardiovascular diseases [94-97] (see Fig. 5). Additionally, the recent clinical data has shown that TMA is formed from precursors like lecithin, choline, betaine, and L-carnitine. These are abundantly present in animal-based dietary components like meat, milk, and fish [96, 98, 99].

TMA is an organic compound produced from dietary quaternary amine components (i.e., L-carnitine and choline) by gut microbiota. Further, TMA is subsequently oxidized by hepatic flavin monooxygenase (FMO) to form TMAO in the liver [93]. TMAO can cause inflammatory reactions of the vascular wall by (i) increasing reactive oxygen species production, (ii) impairing cholesterol metabolism, and (iii) increasing sterol metabolism. These three, when combined, are involved in the formation of plaque in the blood vessel [100]. In addition to an impact on cholesterol and sterol metabolism, TMAO also increases the expression of scavenger receptors such as CD36 and scavenger receptor type 1 on the surface of macrophages. This results in a decrease in reverse cholesterol transport and promotes foam cell formation. Foam cells are also known as lipid-laden macrophages that contain cholesterol inside. In abundance, they can result in the formation of plaque that initiates the progression of atherosclerosis and triggers cardiovascular diseases [96, 98].

\section{A brief note on atherosclerosis lesion formation and its rupture}

With prolonged exposure to risk factors, it is observed that early fatty streak development begins in childhood and adolescence. Further, early fibroatheroma occurs 


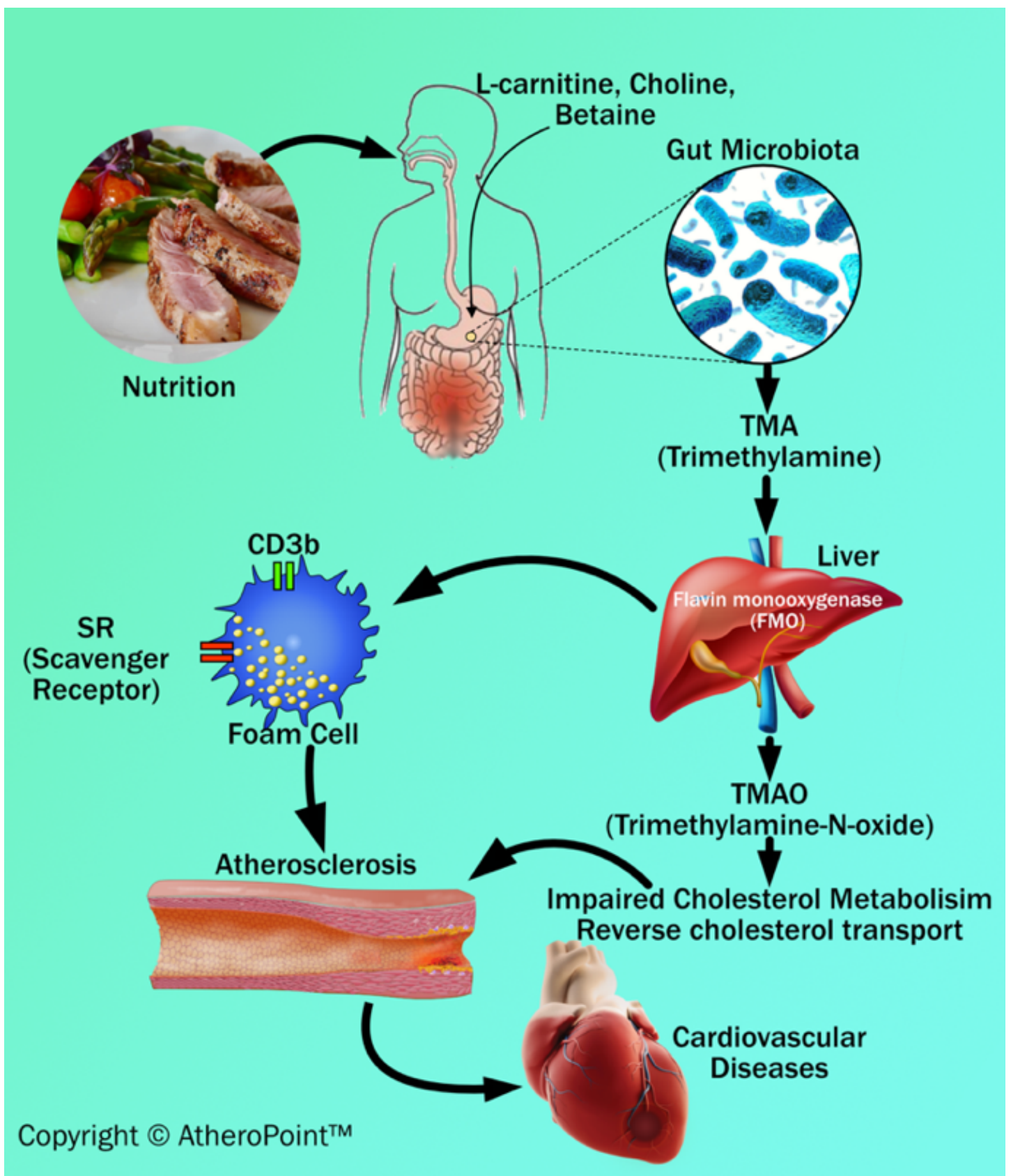

Fig. 5. Dietary adulteration and atherosclerosis development.

in the population in their teenage and young adulthood years [101, 102]. Fig. 6 shows the development of an atherosclerotic lesion in the inner lining of an artery.

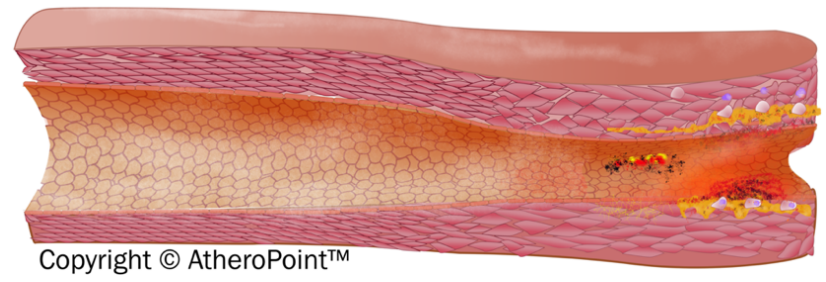

Fig. 6. Development of atherosclerotic lesion.
The initiation of the fatty streak phase of atherosclerosis begins with dysfunctional endothelial cells and the retention of apoB-containing lipoproteins in the sub endothelial space. It is seen that chronic endothelial injury is caused by various factors, including hyperlipidemia, hypertension, smoking, homocysteine, hemodynamic factors, toxins, viruses, or immune reactions. Injury in the endothelial-related region contributes to antithrombotic properties that facilitate the platelet adhesion and activation of the dysfunctional area [10]. The lipoproteins are then modified by the process called oxidation at the extracellular matrix of the subendothelial space [103]. Further, modified LDL promotes the activation of endothelial 
cells (EC) and smooth cells (SCM) and starts the recruitment of immune cells (i.e, monocytes) into the endothelial layer. These recruited immune cells cause a reduction in nitric oxide inside the endothelial wall resulting in endothelial dysfunction, which further triggers the atherosclerosis process [104]. Collectively, an increased monocyte interaction further differentiates into macrophages and leads to the internalization of VLDL, modified LDL, and apoE remnants. This leads to the formation of foam cells [105].

The foam cells are cholesterol-containing lipidladen macrophages that lead to the formation of plaque. The endothelial dysfunction begins as atheroma or benign tumors of smooth muscle cells within the blood vessels. It is characterized by increased permeability, leukocyte adhesion, monocyte adhesion, and emigration. Progression of atherosclerotic plaque is seen when numerous macrophage foam cells and other inflammatory cells continue to promote the formation of other monocytes and immune cells.

The proliferation of tunica-media smooth muscle cells leads to the formation of the fibrous fatty lesion [106]. Vaso Vasorum neovascularization exists in atherosclerosis as a compensatory reaction to provide adequate nourishment and oxygen to atherosclerotic arteries [107]. The developing lesions sometimes represent the next stage beyond fatty streaks and are pearly plaque with dome shape appearance often referred to as “cap”. These lesions may further advance and can be represented as calcified fibrous areas of arteries along with visible ulceration [108]. The plaque, which is covered with a thick fibrous cap and has a well matured necrotic core, is referred to as stable plaque. This fibrous cap proves as an effective barrier in preventing plaque rupture and exposure of prothrombin factors in the vascular pathway [109]. An observation of atherosclerosis is that the macrophage cholesterol pathway becomes inefficient, leading to an imbalance in the lipid metabolisms and cholesterol, further progressing to the disruption of cellular functions [110]. Vulnerable plaque is a result of the unresolved and heightened inflammatory status of the lesions of foam cell core. Data reported in a study indicated that some nutritional and toxic trace metals may have a role in the progression or rupture of plaque [111]. Rupture or erosion of the advanced lesion initiates platelet activation and aggregation on the surface of the disrupted atherosclerotic plaque (see Appendix Fig. 13). Thrombotic vascular occlusion is associated with ischemic episodes, including acute coronary syndromes or cerebral infarction [112].

\section{Nutrition and Carotid B-mode ultrasound imaging}

Nutritional components along with traditional cardiovascular risk factors alone cannot predict the overall risk of atherosclerotic CVE. Such traditional risk factors neither provide any information about the presence or absence of atherosclerotic plaque nor capture morphological varia- tions in atherosclerotic plaque burden [113, 114]. Due to this limitation, many moderate to high-risk patients remain asymptomatic and undiagnosed from most atherosclerotic diseases [115]. This limitation enables the need for imaging modalities that not only can visualize the atherosclerotic plaque, but also significantly contribute to the CVD risk assessment [113, 116, 117].

Some of the popular imaging modalities are magnetic resonance imaging (MRI) [118-120], computed tomography angiography (CTA) [121], optical coherence tomography (OCT) [122], and positron emission tomography (PET). Each of these imaging modalities offers a unique capability of visualization and characterization of atherosclerotic plaque components. However, since imaging using these modalities is expensive and time-consuming, they are generally not preferred by the physician for preventive screening of patients and CVD risk assessment [28].

\subsection{Carotid image-based phenotypes}

Carotid B-mode ultrasound (BMUS) is a comparatively less expensive and user-friendly imaging modality [4, 28, 123-126]. Therefore, it has a wide scope to be used for routine preventive screening of atherosclerotic plaque and CVD risk assessment [51, 70, 123, 127-130]. Automated systems have been well developed for image phenotype measurements [131-134] and validated using CT, MRI, and the gold standard [135, 136]. Recent studies have demonstrated the ability of carotid ultrasound image-based phenotypes such as carotid intima-media thickness (in common carotid or bulb region [137]), total carotid plaque area, carotid intima-media thickness variability (cIMTV) [138], maximum plaque height [139], and morphology of the plaque play a vital role in the prediction of risk of CVE [31, 70, 128, 140, 141]. Studies have also indicated that these carotid image-based phenotypes when combined with traditional cardiovascular risk factors have improved in their prediction ability [70, 128, 129]. Several studies have indicated an annual progression of cIMT and carotid plaque with the traditional risk factors [142-146].

\subsection{Nutrition and carotid IMT}

Similar to the traditional risk predictors, these carotid atherosclerosis biomarkers are also associated with several nutrition-based components [147-149]. Several studies have indicated a regression in cIMT by adhering to the Mediterranean diet in patients with elevated cIMT [150152]. A recent randomized controlled trial by Sala-Vila et al. [153] indicated the progression of cIMT in the internal carotid artery by $0.052 \mathrm{~mm}$ in the group with a control diet. On the contrary, the regressive effect of ICA-cIMT (regression by $-0.030 \mathrm{~mm}$ ) was observed in the group that was taking the Mediterranean diet. Petersen et al. [154] presented a randomized controlled trial that demonstrated the reduction in the progression rate of cIMT in diabetes patients when dietary quality was improved for a year. Their trial indicated 
regression of cIMT by $-0.02 \pm 0.04 \mathrm{~mm}$ in the treatment group, who maintained the quality of diet for one year, and by $-0.004 \pm 0.04 \mathrm{~mm}$ in the control group who continued consuming the usual diet pattern. Another randomized trial by Chiavaroli et al. [155] indicated a significant inverse association of cIMT with nutrition components such as pulse intake $(\beta=-0.019, p=0.009)$, carbohydrates $(\beta=-0.004, p$ $=0.008)$, glycemic load $(\beta=-0.001, p=0.007)$, and starch $(\beta=-0.126, p=0.010)$. Similarly, their study indicated a direct association of cIMT with the total $(\beta=0.004, p$ $=0.028)$ and saturated fat intake $(\beta=0.012, p=0.006)$. It has been proved that intake of green vegetables, fresh, nutritious foods, fruits, and water reduces the cIMT and indicated reduced serum cholesterol levels [147, 148].

Similarly, diet-related metabolites such as LLysine and L-Carnitine are also associated with reduced cIMT [147]. Another randomized control trial of a twoyear follow-up indicated a significant $5 \%$ reduction in the carotid vessel wall volume (VWV) and $-1.1 \%$ change in the cIMT from baseline with dietary weight-loss strategies such as following low-fat, Mediterranean, or low-carbohydrate diets [156]. Fig. 7 (Ref. [156]) depicts the changes in the vessel wall volume of the common carotid artery at baseline and follow-up for the population consuming a low-fat diet (Group 1), the Mediterranean diet (Group 2), and lowcarbohydrate diet (Group 3). Besides all this, the adoption of Western diet plans is associated with increased cIMT in the common carotid artery and leads to adverse vascular events [149]. A recent study indicated that patients with ischemic stroke, especially with carotid atherosclerosis, have a high intake of saturated fatty acids and low consumption of fruits, vegetables, and unsaturated fat nutrients [157].

\subsection{Need for an integrated CVD risk calculator}

Looking at the profound association between carotid atherosclerosis and nutrition components, there is a need to design an accurate diet quality index metric. This will assess the nutrition quality and predict the carotid plaque burden, supporting the CVD risk assessment of patients. Currently, the Diet Quality Index (DQI) questionnaire is available, but it does not show significant linkage with the carotid atherosclerotic plaque burden [158]. Further, traditional risk predictors along with carotid ultrasound image-based phenotypes and nutrition components could be useful in providing the long-term CVD risk of participants. Therefore, there is wide scope to develop such an integrated risk calculator for preventive CVD risk assessment.

\section{Cardiovascular screening and risk stratification}

Knowing the role of nutrition in the formation of carotid atherosclerosis can determine a severe cerebrovascular or cardiovascular event. It becomes essential to un- derstand different ways in which cardiovascular risk can be predicted particularly via vascular imaging or left ventricle imaging [159]. At present, several cardiovascular risk prediction algorithms are available that consider traditional risk factors as input and provide an estimation of the overall cardiovascular risk of patients on the scale of $0 \%$ to $100 \%$. Recently, the American College of Cardiology (ACC) and American Heart Association (AHA) recommends the use of pooled cohort risk equation (PCRE) to predict atherosclerotic cardiovascular risk [160-168]. Similar to the PCRE, there are several other popular conventional cardiovascular risk calculators such as Framingham risk score, Reynold's risk score, the systematic coronary risk evaluation calculator, and QRISK3 [169-174]. The primary idea behind using these conventional risk prediction algorithms is to identify the patients with a high risk of CVD and initiate statin therapy (see Table 1, Ref. [163, 166, 175-179]) to lower down the atherosclerotic plaque buildup [160-168]. ACC/AHA recommended the initiation of statin for CVD risk prevention when PCRE $>7.5 \%$. Similarly, Canadian guidelines recommended the initiation of low-to-moderate statins for FRS $\geq 20 \%$ [175, 176]. The National Institute for Health and Care Excellence (NICE) guidelines recommended the initiation of atorvastatin $20 \mathrm{mg}$ daily if QRISK2 is $\geq 10 \%$ [177-179].

\subsection{Current challenges with CCVRC}

Besides the widespread use of CCVRC, there are several challenges while performing risk stratification in a diverse population. The CCVRC is mainly derived using the regression-based models that handle only a limited set of risk predictors such as patient demographics and clinical parameters. Such traditional risk predictors do not provide any information about atherosclerotic plaque-build or morphological changes in the plaque. Another challenge with such regression-based risk prediction algorithms is that such algorithms assume a linear relationship between the risk predictors and the endpoints. This oversimplification of complex non-linear relationships present in the risk predictors limits the ability of CCVRC to accurately estimate the CVD risk. Because of these challenges, there is an increasing need to look for better solutions that can provide more accurate and robust preventive CVD risk assessment.

\subsection{Integration of image phenotypes with blood} biomarkers

Recently some efforts were made to integrate the traditional risk factors with the carotid ultrasound imagebased phenotypes such as cIMT and plaque area [28, 48, 70, 129]. cIMT and plaque area capture the morphological plaque variations and are considered as the surrogate biomarkers of coronary artery disease (Fig. 8). Therefore, when such an integrated approach was compared against the CCVRC, it reported improved risk stratification.

The AECRS2.0 is an integrated risk prediction algorithm that is comprised of 13 predictors, including 5 


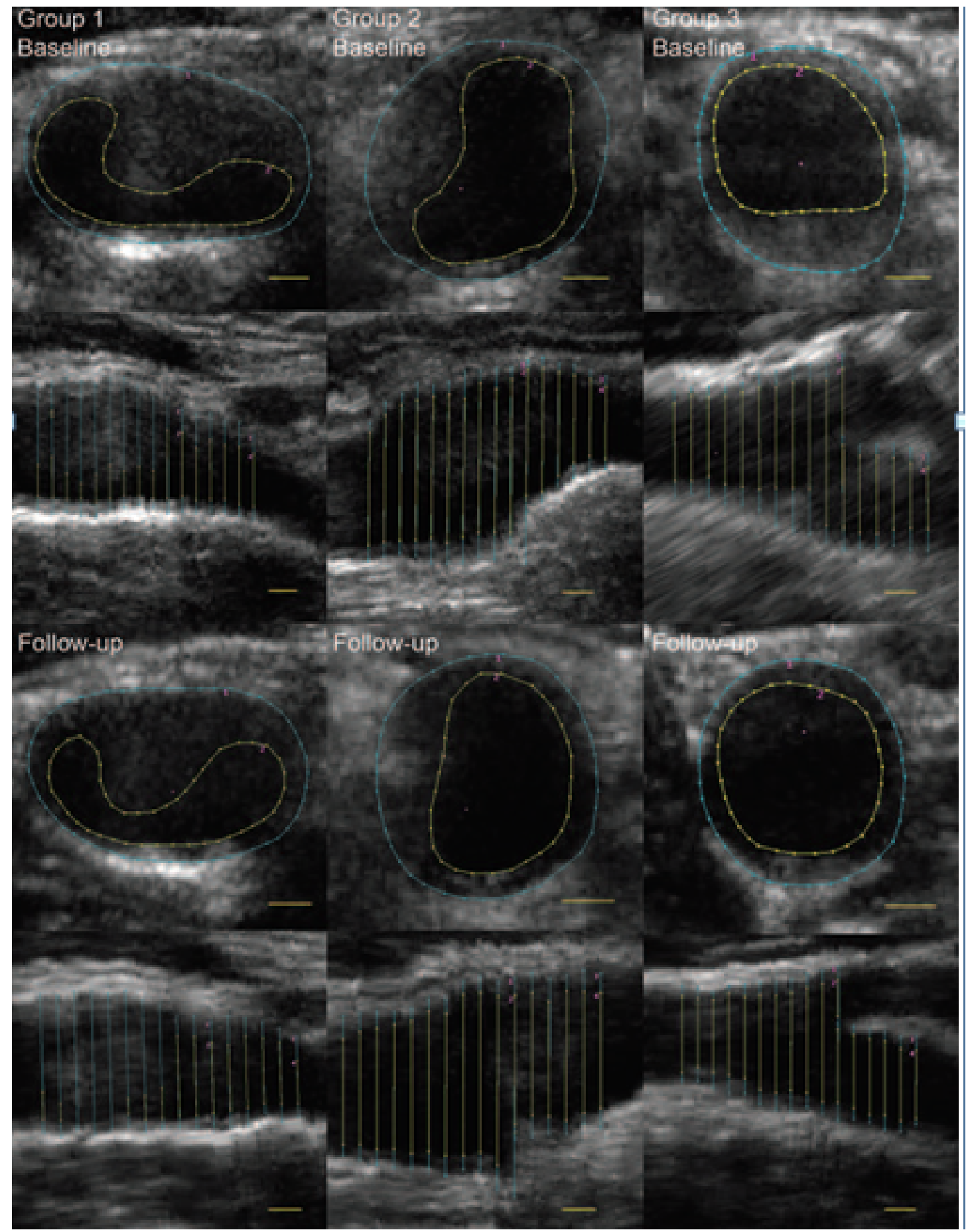

Fig. 7. Carotid ultrasound scanning (with permission from Circulation [156]).

carotid ultrasound image-based phenotypes [128]. The independent contribution of each risk predictor in the 10-year CVD risk is shown in Fig. 9 and is preferred as a preventive screening tool [35]. This tool has been applied to the bulb region and correlated to renal scores [50, 180-182] or rheumatology patients [183].
8.3 Role of artificial intelligence in risk stratification

Another way of improved risk assessment is to use artificial intelligence (AI)-based algorithms for cardiovascular risk stratification. AI-based algorithms can handle a large number of risk predictors in their model. Therefore, diverse types of risk predictors could be included in the risk prediction algorithm. Further, since AI-based algorithms are data-specific algorithms, they capture and learn from the complex non-linear interrelationship among the 
Table 1. Risk thresholds for statin initiation.

\begin{tabular}{lcc}
\hline Guideline & Risk score & Cut-off with statin initiation \\
\hline ACC/AHA 2013 guideline [163] & $\begin{array}{c}\text { Pooled Cohort } \\
\text { Risk Score }\end{array}$ & Cut off of $\geq 7.5 \%$ for initiation of moderate to high-intensity statin \\
NICE 2014 guideline [177-179] & QRISK2 risk engine & Offers atorvastatin 20 mg daily who have a score $\geq 10 \%$ \\
Canadian 2012 guideline [175] & FRS CVD risk score & Cut off of $\geq 20 \%$ for statin initiation \\
U.S. Preventive Services Task Force [166] & Pooled Cohort & Low-to-Moderate dose of statin in Risk $\geq 10 \%$ \\
\end{tabular}
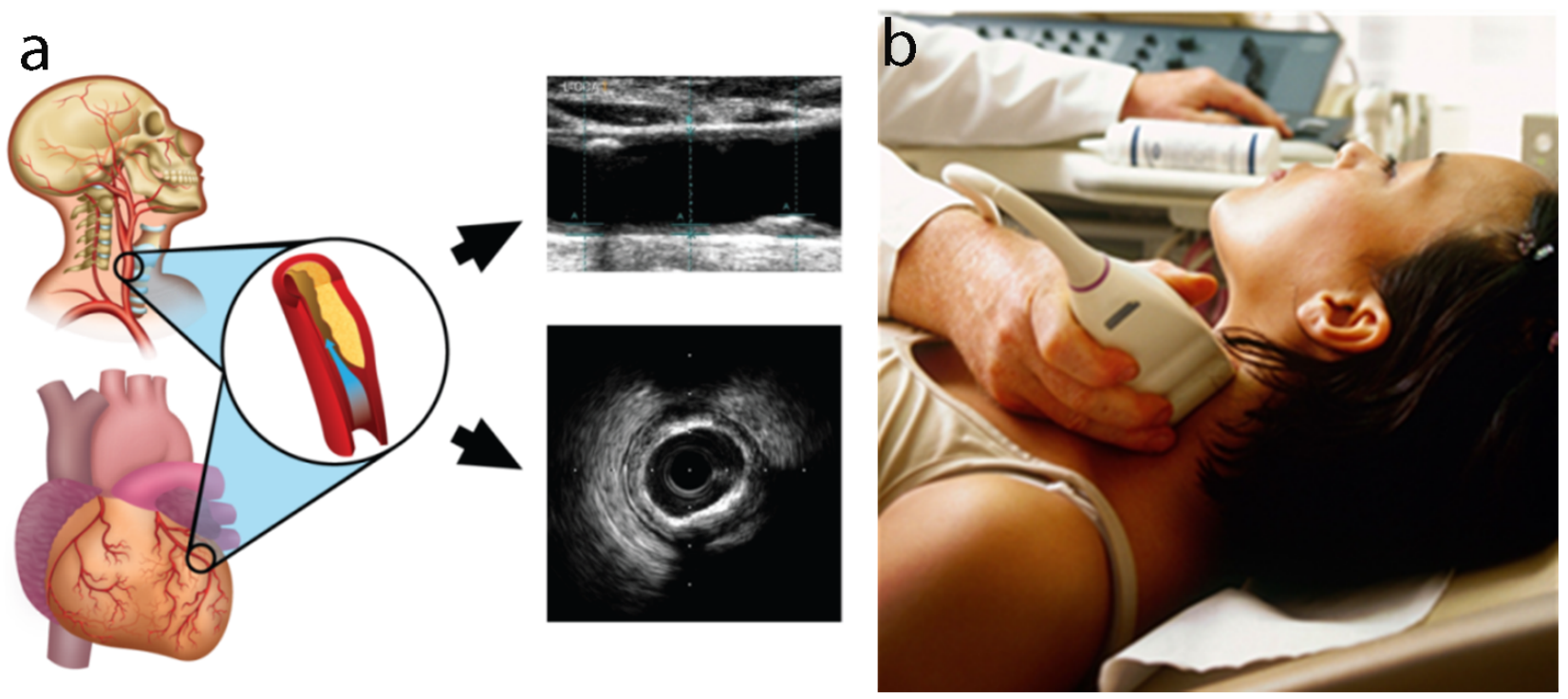

Fig. 8. Carotid ultrasound imaging for preventive CVD risk screening. (a) Carotid artery being used as a surrogate marker for coronary artery. (b) Imaging device.

risk predictors [123]. This characteristic makes AI-based algorithms unique compared to CCVRC. Recently, several studies have demonstrated the superior performance of AIbased algorithms over the CCVRC. A recent study by Kakadiaris et al. [184] reported the outperformance of ML-based atherosclerotic CVD event prediction over the conventional PCRE (0.92 vs. 0.71). The authors demonstrated that the PCRE over-recommended the statin to nearly $46.0 \%$ of the selected population. However, the AI-based algorithm recommended statin to $11.4 \%$ population who required the initiation of statin therapy.

Another study by Weng et al. [185] also supported the outperformance of AI-based algorithms over the PCRE for CVD risk assessment. Knowing that the integration of carotid ultrasound image-based phenotypes can provide better CVD risk assessment, Jamthikar et al. [130, 186] presented a study to compare the AI-based algorithm against the 13 different types of CCVRC for CVD risk assessment (Fig. 10, Ref. [186]). In their study, AI-based algorithms showed an overall risk-stratification accuracy of 92.52\%, which was higher compared to all the 13 types of CCVRC. The authors also showed the role of machine learning for better risk prediction that used carotid ultrasound plaque characteristics to improve the risk stratification accuracy [187, 188]. The same authors also supported their claim of superiority of AI-based algorithm over CCVRC in a recent study that predicted multiclass risk profile in Canadian patients [140]. A comparison between AI-based vs. statistical-based calculators can be shown in Fig. 10 [186]. Such ML-based strategies for office-based settings are now available [31].

8.4 A note on plaque tissue characterization for stroke risk stratification

Ultrasound-based Tissue characterization (UTC) is one of the upcoming methods to morphologically evaluate the tissue that is at risk. The team has developed several applications of UTC in several organs such as the thyroid [189, 190], arrhythmia [191], liver [192], prostate, cardiovascular, etc. The potential of AI-based algorithms has also been explored in the domain of atherosclerotic plaque tissue characterization. Studies have been conducted to risk stratify the carotid ultrasound images into symptomatic and asymptomatic plaques $[193,194]$. This study indicated an overall tissue characterization accuracy of $90.66 \%$ using the AI-based algorithm. Another study by Lekadir et al. [195] used the deep learning model, called the convolutional neural network, to identify different carotid plaque components such as the lipid core, fibrous cap, and calcified tissues with a classification accuracy of $78.5 \%$. 

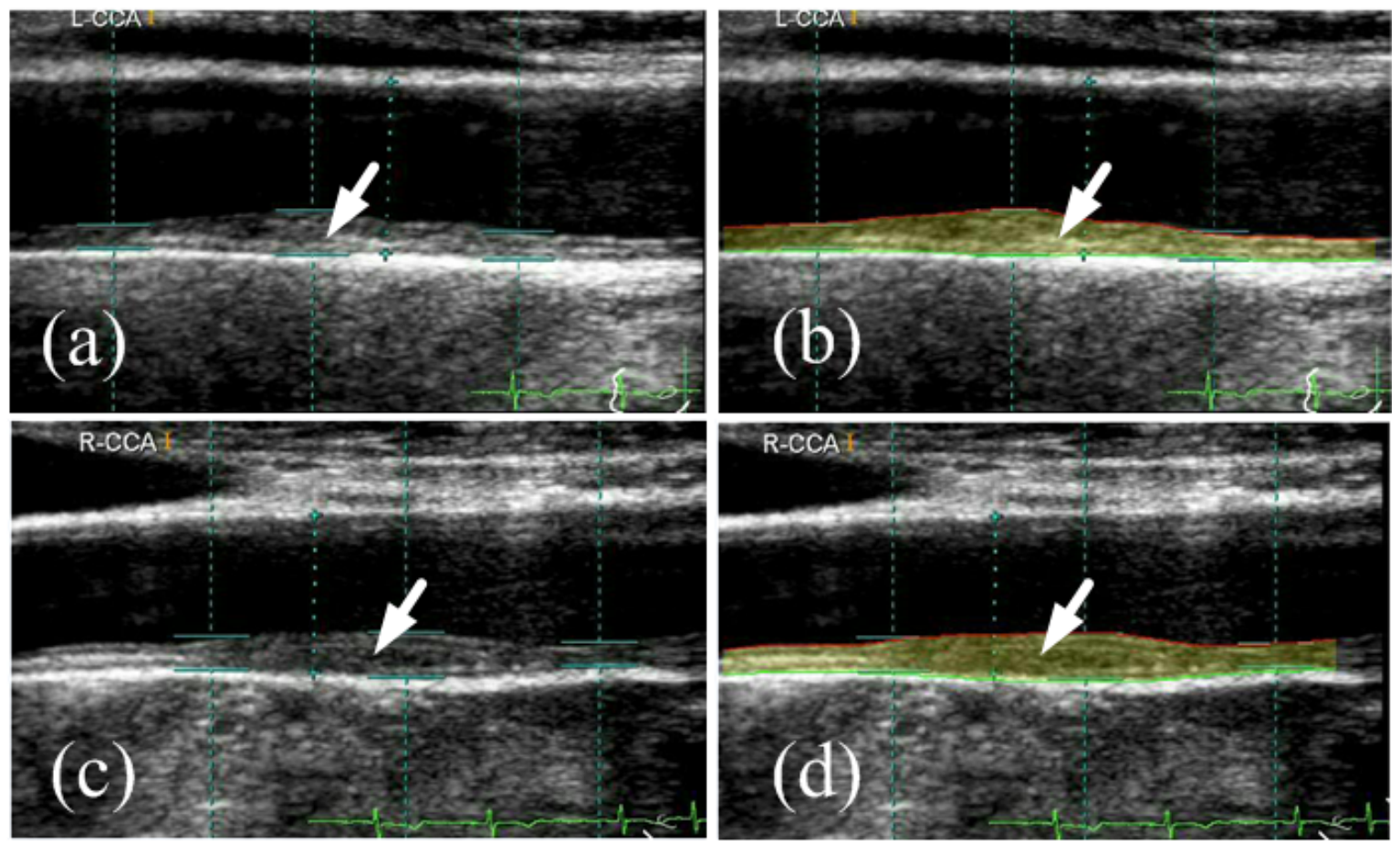

\begin{tabular}{|c|c|c|c|c|c|c|c|c|c|c|c|}
\hline \multicolumn{4}{|c|}{ Left Common Carotid } & \multicolumn{4}{|c|}{ Right Common Carotid } & \multicolumn{4}{|c|}{ Mean } \\
\hline SN & Biomarker Type & Color & $\%$ Contribution & Ss & Biomarker Type & Color & $\%$ Contribution & SN & Biomarker Type & Color & $\%$ Contribution \\
\hline 1 & 5 Image Phenotypes & & 62.78 & 1 & 5 Image Phenotypes & & 69.18 & 1 & 5 Image Phenotypes & & 65.98 \\
\hline 2 & ESR & & 4.15 & 2 & ESR & & 3.92 & 2 & ESR & & 4.04 \\
\hline 3 & eGrR & & 2.18 & 3 & eGrR & & 2.16 & 3 & eGFR & & 2.17 \\
\hline 4 & BMI & & 0.91 & 4 & BMI & & 0.93 & 4 & BMI & & 0.92 \\
\hline 5 & HbAlc & & 0.89 & 5 & $\mathrm{HbAlc}$ & & 0.89 & 5 & HbAlc & & 0.89 \\
\hline 6 & Age & & 0.76 & 6 & Age & & 0.76 & 6 & Age & & 0.76 \\
\hline 7 & Lipids & & 0.08 & 7 & BP & & 0.70 & 7 & BP & & 0.37 \\
\hline 8 & BP & & 0.04 & 8 & Lipids & & 0.08 & 8 & Lipids & & 0.08 \\
\hline 9 & No-Risk & & 28.21 & 9 & No-Risk & & 21.38 & 9 & No-Risk & & 24.79 \\
\hline
\end{tabular}

Fig. 9. Independent contribution of risk predictors in the 10-year CVD risk profile of a patient estimated for the left common carotid artery, right common carotid artery, and mean of left and right common carotid artery [AtheroEdge ${ }^{\mathrm{TM}}$ 2.0]. (a,b) Original and reproduced ultrasound scans for moderate-risk patient. (c,d) Original and reproduced ultrasound scans for high-risk patient. (e) Independent contribution of risk predictors in the 10-year CVD risk. The figure was reproduced with permission [46] (courtesy of AtheroPoint, Roseville, CA, USA).

Looking at the broader view of the discussion, it is clear that an AI-based algorithm should be used for accurate cardiovascular disease risk assessment. Further, a combination of traditional risk factors along with carotid ultrasound plaque phenotypes should be used for preventive screening of patients for atherosclerosis and risk estimation. Another point to note was that although there were attempts made to predict the CVD risk in machine learning using nutrition components [196, 197], there is still a wide scope to investigate the efficacy of ML-based CVD risk assessment and event prediction using a combination of nutrition, traditional risk factors, and the image-based biomarkers of atherosclerosis.

\section{Management of atherosclerosis via nutrition pathway}

Although there are several pharmacotherapies available to treat atherosclerosis and reduce the overall mortality rate, CVD is still the top challenge global healthcare providers are facing. Therefore, there is a need to look for an additional treatment strategy that can go hand-in-hand 

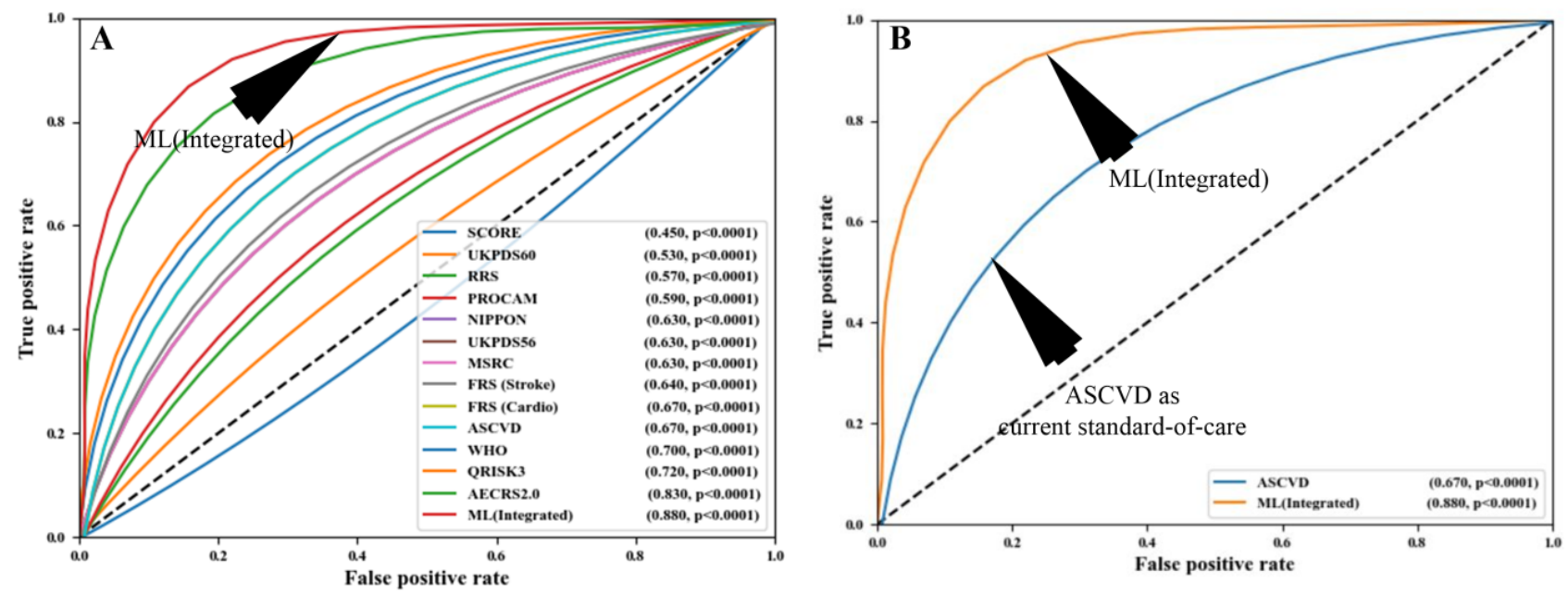

Fig. 10. Comparing the ML-based CVD risk assessment with conventional calculators. (A) Comparing ML-based system with 13 types of CCVRC and (B) comparing ML with the standard-of-care ASCVD calculator (Reproduced with permission [186]).

with existing therapies. A nutritious diet and lifestyle modification, even at an early age, has proven to be an effective solution for the prevention of CVD [198-203]. Nutraceuticals are natural nutrition-based compounds that provide health benefits and are used in preventing atherosclerotic CVD [204, 205]. They are generally categorized into either dietary supplements or functional foods [204, 205].

Polyunsaturated fatty acids (PUFA) are the essential type of dietary supplements that are generally used in the (i) regulation of blood pressure and blood clotting and (ii) in the modulation of the inflammatory response by forming the eicosanoids mediators [205]. PUFA are generally divided into two types such as omega-3 PUFA and omega-6 PUFA. Rich sources of omega-3 PUFA are fish oil, nuts, and flax seeds. The benefits of Omega-3 PUFA are well-known over the past decades [206]. In addition, American Heart Association (AHA) has recommended eating 200 grams of oily fish every week [207]. Fish oil or fish oil supplements have shown a reduced risk of atherosclerotic markers. Omega-3 PUFA contains eicosapentaenoic acid (EPA) and docosahexaenoic acid (DHA), both helpful in CVD prevention [205, 208]. Low levels of DHA and EPA both are associated with reduced endothelial function, which may further lead to arterial stiffness [209]. This stage can be improved by daily consumption of omega-3 PUFA for a minimum of 12 weeks [210]. A Japan EPA Lipid Intervention Study (JELIS) trial with 18645 Japanese patients showed a $19 \%$ reduction in the risk of major cardiovascular events in a group taking statin and 1.8g of EPA than the group that statin alone [211]. A very recent REDUCEIT trial also investigated the effectiveness of using a pure form of EPA in patients with elevated triglyceride levels [212]. This study also showed a reduction in overall ischemic events, including cardiovascular deaths, among patients who received $2 \mathrm{~g}$ icosapent ethyl twice daily [212]. Thus, omega-3 PUFA can reduce the risk of arrhythmia and thrombosis by slowing down the rate of atherosclerotic plaque build up [207, 213]. Therefore, it must be part of the treatment plan for CVD prevention.

As discussed in section 6, the Mediterranean diet (MedDiet) is considered one of the most popular functional food diets that offer several preventive benefits for cardiovascular health [214-217]. A well balanced Mediterranean diet includes (i) high intake of minimal processed plantbased food such as vegetables, fruits, whole-grains, and nuts, (ii) high consumption of monosaturated rich fat from fish, olive oil, and (iii) lower intake of saturated fats, meat, and dairy products [218]. Recent studies have indicated a reduced risk of myocardial infarction, heart failure, and stroke by strictly adhering to the MedDiet [219, 220]. Even diabetic patients who have a high chance of dying due to CVD have shown a reduction by $30 \%$ in the mortality rate by each 2 point increase in the MedDiet score [221, 222]. Another major PREDIMED study also indicated a reduction in the composite CVD risk by $30 \%$ when following the MedDiet supplemented with olive oil and nuts [223]. Paterson et al. [220] presented a 17-year follow-up study which demonstrated a population strictly adhering to the MedDiet has a reduced risk of stroke events. Due to the widespread benefits of MedDiet, it can be considered as a primary choice for food intake. As a result, the physicians have recommended this diet for preventing atheroscleroticdriven CVD-related events.

Besides the MedDiet, several studies have shown the reduction in overall CVD risk with an appropriate intake of foods containing soluble fiber [224-227], plant sterols/stanols [228], B3 vitamin-like Niacin [229], vitamin E, vitamin C [230], vitamin D [231-234], and amino acids like Taurine [235]. Along with this, time-restricted eating also proves beneficial in managing obesity and thereby preventing CVD [236]. Most of these nutrition components generally target the reduction of LDL cholesterol and in- 
crease in HDL cholesterol level, [10] thereby reducing the atherosclerotic plaque build-up and CVD events.

\section{Inter-relationship between nutrition, COVID-19, and atherosclerosis}

COVID19 is a highly transmittable and pathogenic viral infection that is caused by severe acute respiratory syndrome coronavirus 2 (SARS-CoV-2) [237]). It has led to a dramatic loss (nearly infecting 155 Million and perishing 3.3 Million people as of 5th May 2021) of life worldwide [238].

10.1 Acute respiratory distress syndrome due to COVID-19

Several studies have suggested that COVID-19 severely affects the lungs of an individual and has adverse effects on other organs of the body [239]. It is seen that the increased mortality due to SARS-CoV-2 is mainly due to viral pneumonia induced Acute Respiratory Distress Syndrome (ARDS) [240]. ARDS leads to lung damage (refer to Appendix Fig. 14). SARS-CoV-2 enters the lungs via aerosol transmission, which further attaches to the host cells. This leads to respiratory symptoms that can be categorized as the earliest clinical presentation of COVID-19 [44].

10.2 COVID-19 and pathways leading to brain/heart injury

Imaging has shown to be very useful in understanding COVID-19 severity [241, 242]. Comorbidity has been shown to affect the lungs and heart more aggressively [45, 46, 49]. SARS-CoV-2 causes brain and heart injuries via different pathways (as seen in Fig. 11).

\subsection{Impact of COVID-19 on nutrition}

During the SARS-CoV-2 outbreak, governments have imposed a quarantine to reduce the spread of the virus. This quarantine is an unpleasant experience that is causing changes in lifestyles such as unhealthy nutritional habits [243]. In this section, we illustrate how nutrition and lifestyle changes during COVID-19 affect atherosclerosis [244]. Alteration of nutritional habits is occurring because of the reduced availability of fresh food and its replacement with unhealthy food due to restrictions in the opening of stores.

A recent clinical journal on the psychological impact of quarantine also reported negative effects, including post-traumatic stress symptoms like depression, confusion, and irritability [245, 246]. An increase in consumption of packaged foods, frozen foods, and reduced consumption of fresh foods like fruits and vegetables are major consequences of weight gain. Increased weight gain with reduced consumption of fresh food results in a decrease in antioxidants in the body. Additionally, physical inactivity with oxidative stress increases the risk of atherosclerotic plaque formation [247-249]. COVID-19 has direct effects on basic, underlying, and immediate drivers of acute and chronic malnutrition. Several sectors like (a) food insecurity due to poor-quality diets, (b) reduced income because of limited financial resources, (c) limited care and restricted health services, (d) interrupted education for children and adults, and (e) an unhealthy household environment are critical to reducing childhood undernutrition at particular risk of collapse or reduced efficiency due to widespread impact of COVID-19 [250]. It is very important to focus on the importance of nutrition to boost immunity and to keep professional and authentic dietary guidelines about nutrition and food safety to withstand COVID-19 [251, 252]. Therefore, utmost nutritional practices need to be figured out to provide critically ill patients with utmost enteral and parenteral nutrition as required $[253,254]$.

\subsection{Nutritional therapy and COVID-19}

The immune system protects the host from pathogenic organisms. Virally infected cells directly activate natural killer cells which act to kill the infected cell. The processes involved in antiviral immunity are therefore linked to various nutritional consequences [255]. Patients with critical COVID-19 conditions should be included in life-saving therapies in which nutrition plays a great role. The supplementation of amino acids and lactoferrin must be accompanied by drug therapies followed by an ICU hospitalization. It is seen that lung damage caused by coronavirus is from the overexpression of proinflammatory molecules (cytokines) which has shown to be lowered by an adequate integration of amino acids.

Nutritional therapy, together with pharmacological therapy, undoubtedly helps the COVID-19 patient to overcome the acute phase of the disease first and to shorten recovery time [256]. Inflammatory molecules are involved in infection, and certain dietary components, including cytokines, growth factors, and other components, may interact with them [257]. Nutrition modulates disease severity and progression. Nutritional status has the potential to influence susceptibility to the risk of COVID-19 through its integral role in immune function. For example, micronutrients support mucosal immune function (vitamin A), epithelial tissue integrity (vitamins $\mathrm{A}, \mathrm{C}$, and D), enhancing the function of certain adaptive and innate immune cells (vitamins A, C, D, E, iron, zinc, and PUFAs) and potential pro-oxidant effects (vitamin C) [258]. Obesity and related comorbidities like endothelial risk function, altered Interferon production, oxidative stress, sarcopenia, and insulin resistance, increased ACE2 inhibition in adipose tissues can lead to cytokine storm, impaired immune response, thrombotic events, which further make an individual more prone to infection and transmission of COVID-19 [259-265]. 


\section{Effect of Nutrition and COVID-19 on Atherosclerosis and plaque formation leading to Brain/Heart injury}

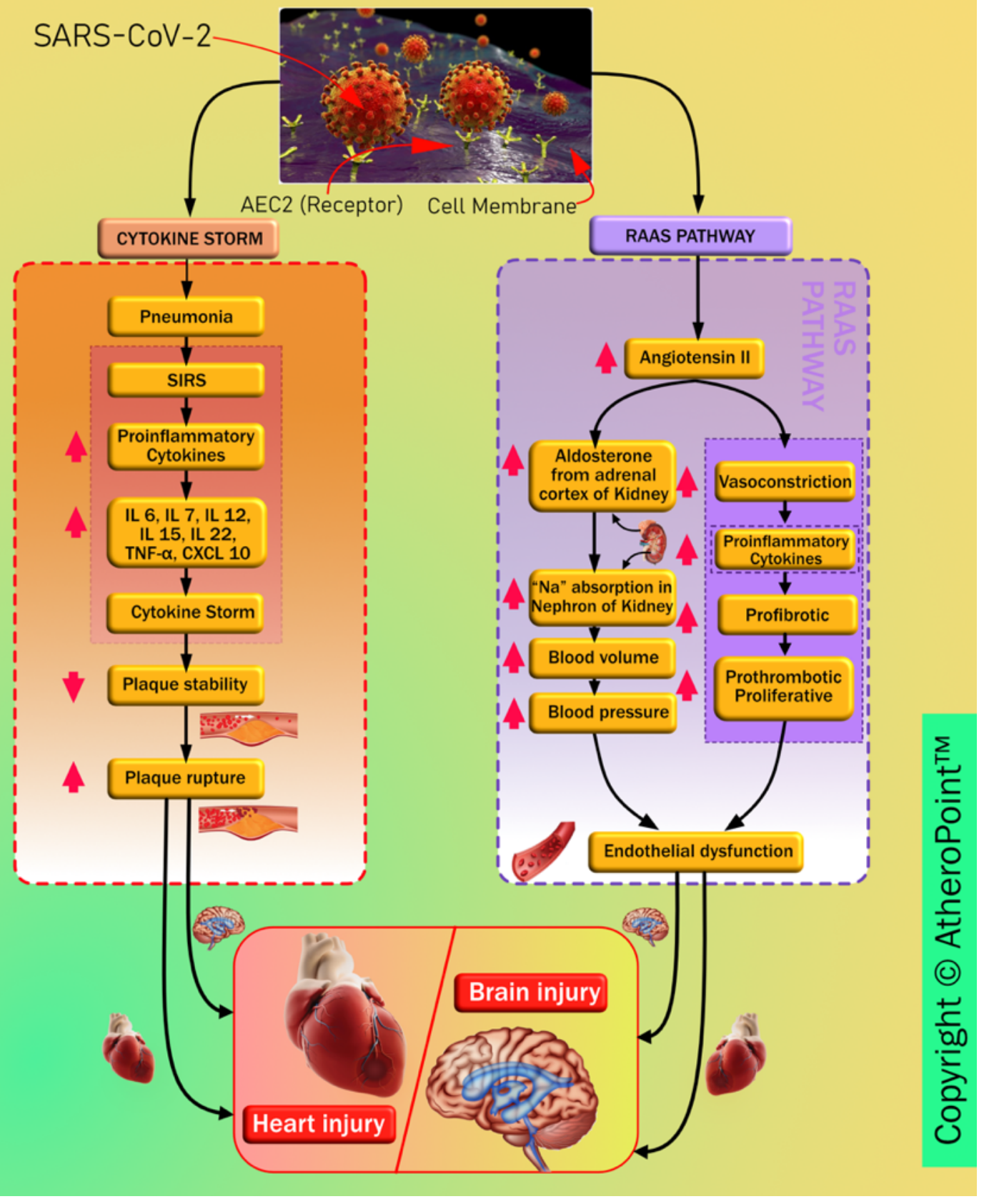

Fig. 11. Pathways linking COVID-19 to heart and brain injury.

\subsection{COVID-19 association with underlying conditions}

Trends have shown a worsening of cardiac events in COVID-19 patients with underlying conditions such as coronary artery disease, hypertension, and diabetes mellitus [266]. Many reports from admitted patients have also suggested cardiac injury in about $12 \%$ to $26 \%$ of them. This exists due to the presence of pericytes in the heart, which have a high expression of ACE2 that are the same receptors through which the virus gains entry into the cells of the body. The cytokine released during the infection could affect the intramural coronary vessels of the patients. It is also seen that cardiovascular diseases have a major effect on ARDS in patients with COVID-19 affected lungs [239].

Some studies also suggest that abnormal immune system response is likely to be the underlying cause of myocardial injury during coronavirus infection. Thus, it is suggested that potential cardiac involvement should be identified early to provide a prompt diagnosis for improving the 
outcome [45]. It is noted that the consequences of dysregulation of the renin-angiotensin system caused by SARS$\mathrm{CoV}-2$ inside atherosclerotic plaques lead to endothelial dysfunction. This progresses into thrombosis, which in turn favours the invasion of plaque by inflammatory cells. These events may transform vulnerable plaque into a complicated and ruptured plaque [267]. Some studies also suggest that if positive for SARS-CoV-2 and asymptomatic, patients could be at increased risk of developing cerebral ischemic strokes, and myocardial infarction due to increased instability of coronary and carotid plaques [49, 268].

As mentioned above COVID-19 patients develop several complications, among these is the elevated level of IL-6 (interleukin-6). It is responsible for signalling the liver to increase the synthesis and secretion of C-reactive protein (CRP) levels [269]. Higher CRP levels in the blood are diagnostic of extensive tissue damage and pathological inflammatory response. It was observed that at the early stage of COVID-19, CRP levels were positively correlated with the diameter of lung lesions and the severity of COVID-19 [270]. Moreover, CRP levels can be measured and used as a lab-based blood biomarker, which is a simple, affordable, and rapid way to assist the therapeutic conditions and to evaluate the severity of the disease [269]. Thus, CRP levels are also seen to be an effective diagnostic tool in measuring the severity of COVID-19. Anti-inflammatory agents helped in suppressing the elevated levels of IL-6, thus keeping CRP levels in check. In patients with CVD risk, a high burden of subclinical inflammation is associated with COVID-19 development of subclinical disorders or cause cardiovascular damage [271]. However, nonsteroidal antiinflammatory drugs (NSAID) should be avoided in patients with a high risk of cardiovascular disease as they are seen to increase the risk of heart attack, stroke and high blood pressure [272, 273]. Generally, ACE2 plays an important role in the cellular entry of SARS-CoV2. Additionally, it also affects the renin-angiotensin-aldosterone system (RAAS), which acts as a central mechanism of many drugs including NSAIDs [B7]. An important study also shows the increase of expression of ACE2 levels on heart tissue of diabetic rats after treating with NSAIDs [274].

10.6 The overall architecture of the system and role of AI in the COVID-19 framework

There are two major components for COVID19 screening: (i) primary and (ii) secondary. Fig. 12 shows the pictorial representation of the workflow during COVID-19 screening and diagnosis along with the role of AI for CVD screening.

Primary screening: The patient undergoes screening with the help of a robot and AI in the COVID-19 framework. Questions are asked considering basic symptoms and based on the answers received, the robot analyses and to move forward if there is a need for screening tests like the RT-PCR test (shown as T1, diamond box). Note that the cross-questioning is done when the patient first appears at the clinic or hospital doors. The analysis is done with the help of the AI-based machine intelligence system and telemedicine (TM) right at the outset (shown in the yellow ellipse, where the nurse and robot sign is depicted). Based on the results of the RT-PCR test at the T1 junction (shown in diamond box), the patient needs to be quarantined (Q1, marked yellow) if the test is positive, or the patient is uninfected by COVID-19, if the test is negative (marked green, U1).

Outcome of risk assessment box (SA): While the patient is in quarantine, risk assessment is performed using AI-based system during monitoring (shown using M1). During the monitoring process, the doctor interacts with the patient to understand (a) his lung condition and (b) atherosclerotic arterial condition. The lung condition is evaluated using X-rays/CT imaging embedded with AI. The atherosclerotic arterial condition is evaluated noninvasively using carotid ultrasound for CVD risk. The output of the monitoring function is fed to the risk assessment box (SA), to take appropriate decisions on three fronts: (i) worsening lung condition and need for ICU, or (ii) worsening of CVD condition and need for CVD treatment, and (iii) uninfected.

There are three outcomes from the risk assessment box (SA). (i) The patient's Ground Glass Opacities (GGO) conditions if worsened (from the output of the monitor), however, no atherosclerotic lesions in the carotid arteries, the patient is categorized to be extremely symptomatic, evaluated further in Intensive Care Unit (ICU) under ventilation conditions. This situation is a dire necessity because the lung conditions have started to fill up with fluid (see Appendix Fig. 14). Note that, the patient is continuously monitored in the ICU (shown by monitoring function M2). (ii) If the lung conditions are not worse (very low GGO), while the carotid arteries show plaque burden, the patient undergoes CVD treatment (C). In the last outcome (iii) the patient neither has lung worsening nor arterial deterioration, therefore he is considered uninfected (U2). Note that, since the patient was quarantined (Q1) and the risk assessment (marked as A) was performed using AI based imaging followed by CVD treatment (marked as C), the patient is assessed by the doctor based on clinical judgement (marked as J). Finally, once the patient is uninfected (U2), the long COVID process triggers where the patient can be retested for COVID (secondary screening, marked SS). If found positive, the feedback loop triggers again for quarantine (Q1) or if negative, free from COVID-19 (U3, marked green).

10.7 Role of AI in CVD risk assessment for COVID-19 screening

The role of AI for CVD risk is evaluated using a machine learning system where the imaging data can be taken to predict the CVD risk at the vascular level 


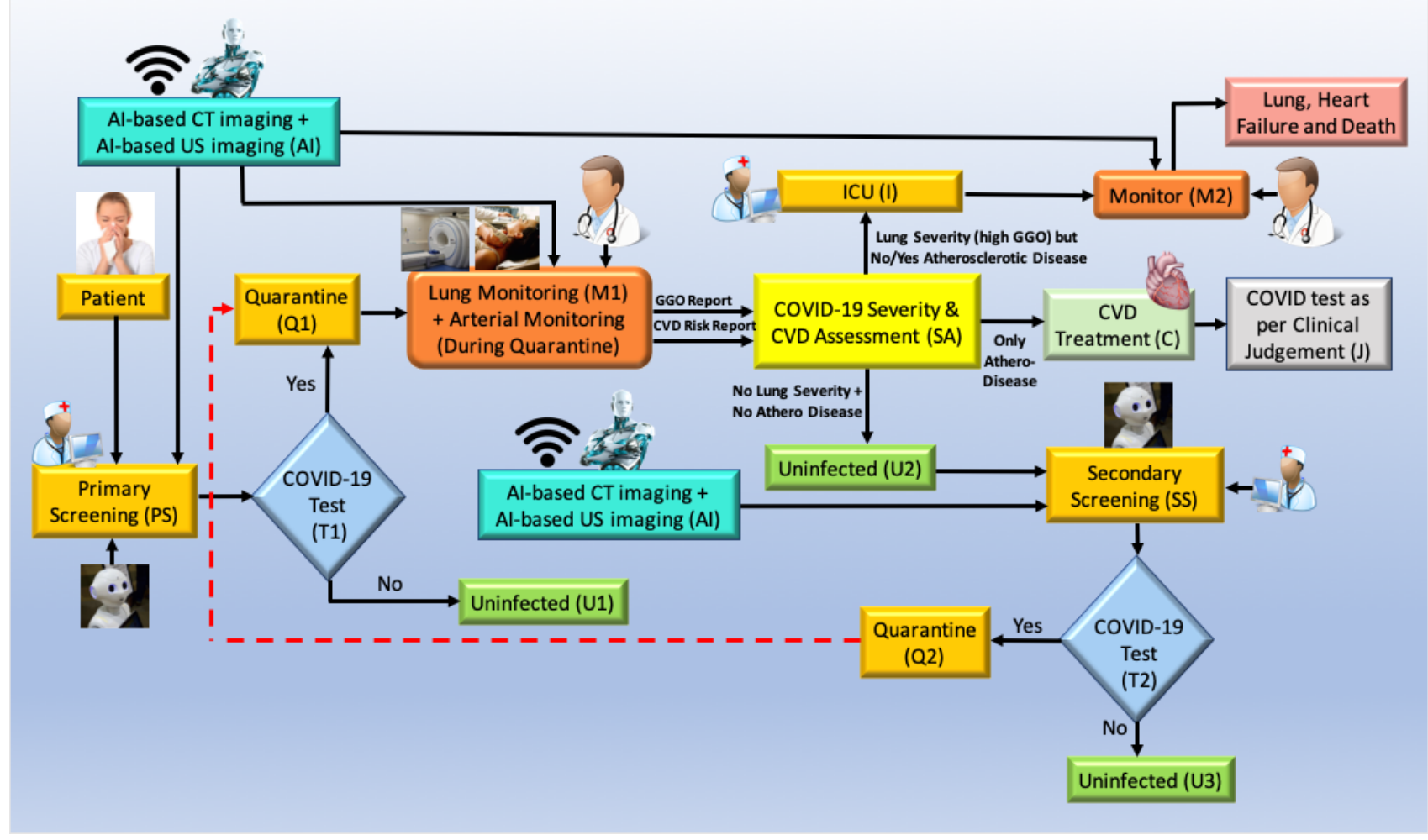

Fig. 12. Role of AI-based CVD risk assessment during pandemic (Courtesy of AtheroPoint ${ }^{\mathrm{TM}}$, CA, USA).

[31, 140, 187]. The idea is to acquire the carotid scans of the patient, collect the plaque image-based phenotypes and predict the risk using a machine learning system. The AI component requires only the trained model shown by green colour labelled as Imaging-based AI with the AI logo of a robot on it. The output of the machine learning system is to tell the clinician monitoring the patient (M1) if the risk of CVD is low, moderate or high. Based on this colour-coded scheme, the patient undergoes CVD risk assessment (marked as SA). This can involve ground-glass opacity evaluation [241] of the CT lungs or if there is any pulmonary embolism [275]. Thus, the concept shows the role of AI-based CVD screening for diagnosis during pandemic times.

\section{Critical discussions}

This review provided an understanding of a complete cycle for tracking the effect of nutrition on heart disease. We studied the link between nutrition and the effect it has on various risk factors to have a clear understanding and isolate direct causes of the disease. A deep insight into the effects of LDL in plaque formation and the development of atherosclerotic lesions is shown in the study. We also provided quantitative wall measurement methods, which can be used for studying the effect of nutrition on atherosclerotic wall formation. With the ongoing pandemic, it is important to make sure that one provides information on how the disease might take its course in an infectious environment. Thus, we explored the link between nutrition and atherosclerosis during the non-COVID-19 and COVID-19 periods. The review presented a pathophysiological link between nutrition and atherosclerosis by gaining a deep insight into the processes involved at every stage of plaque development. Various studies provide evidence on how various foods or other factors might affect atherosclerosis, and thus, we combine and form strategies to diagnose and treat the disease. After targeting the causes and finding out results using low-cost, user-friendly, ultrasound-based arterial imaging, the study showed the role of how to risk stratify and monitor the plaque burden. The study shows the role of AI in efficient CVD risk assessments. Finally, the review presented the role of nutrition and vascular damage due to SAR-CoV-2, leading to brain and heart injury.

Thus our key findings of the study are:

- How nutrition affects the formation of atherosclerosis and plaque formation.

- The role of low-cost surrogate CVD such as carotid ultrasound-based screening which can help in effective AI-based risk stratification and monitoring the atherosclerotic disease.

- Application of AI-based CVD risk assessment during the COVID-19 period.

\subsection{Benchmarking}

Several articles have addressed only a few out of all these aspects, but after a perusal of various studies, we 
Table 2. Benchmarking table for other reviews.

\begin{tabular}{lcccccccc}
\hline Citations & Year & Nutri $^{a}$ & LDL \& Atherogenesis & PL $^{b}$ & PF $^{c}$ & AI $^{d}$ & RS $^{e}$ & COV-19 $^{f}$ \\
\hline Badimon et al. [276] & 2010 & $\checkmark$ & $\checkmark$ & $\times$ & $\times$ & $\times$ & $\times$ & $\times$ \\
Anand et al. [38] & 2015 & $\checkmark$ & $\times$ & $\times$ & $\times$ & $\times$ & $\times$ & $\times$ \\
Torres et al. [10] & 2015 & $\checkmark$ & $\checkmark$ & $\checkmark$ & $\times$ & $\times$ & $\times$ & $\times$ \\
Bolla et al. [277] & 2016 & $\checkmark$ & $\checkmark$ & $\times$ & $\checkmark$ & $\times$ & $\times$ & $\times$ \\
Tarkin et al. [278] & 2016 & $\times$ & $\times$ & $\times$ & $\times$ & $\checkmark$ & $\times$ & $\times$ \\
Casas et al. [279] & 2018 & $\checkmark$ & $\checkmark$ & $\times$ & $\times$ & $\times$ & $\times$ & $\times$ \\
Proposed & 2021 & $\checkmark$ & $\checkmark$ & $\checkmark$ & $\checkmark$ & $\checkmark$ & $\checkmark$ & $\checkmark$ \\
\hline
\end{tabular}

Nutri $^{a}$, Nutrition; $\mathrm{PL}^{b}$, Pathophysiological Link; $\mathrm{PF}^{c}$, Plaque Formation; $\mathrm{AI}^{d}$, Artificial Intelligence; $\mathrm{RS}^{e}$, Risk Stratification; COV-19 ${ }^{f}$, COVID-19.

did not find any study that would address all these links together. Some of these previous studies have been tabulated in Table 2 (Ref. [10, 38, 276-279]).

In a review written by Badimon et al. [276], we observed that it does link an aspect of nutrition to atherosclerosis and provides nutraceutical interventions in the treatment of atherosclerosis by discussing various effects that nutraceuticals might have on the body. However, they do not talk about various other attributes that are necessary to provide a holistic approach towards the disease.

In another study conducted by Anand et al. [38], a link between various foods, macronutrients, and CVD was established; therefore, it did not target atherosclerosis but instead gave a broader outlook towards nutrition and its link to CVD. This is also seen in the review by Casas et al. [279] who talks about nutrition and cardiovascular health as a whole. Further, Torres et al. [10], in his review, gave a very vast review on nutrition and atherosclerosis, but to target, the disease as a whole, the imaging techniques, its link with AI, and many other aspects were not mentioned in their review. A similar missing component was also observed in the article by Bolla et al. [277], who also discusses, in brief, the pathophysiological link between nutrition, but does not address other factors related to the disease. Tarkin et al. [278], in their review, talks about the imaging techniques, but apart from that, the whole nutritional component is missing. Hence, to our understanding, no other paper has provided the same approach towards the disease which is necessary to study the disease and provide interventions in its treatment.

\subsection{Recommendations}

It is well established that nutrition plays a major role in the formation of plaque as well as in the risk factors, individually contributing to the progression of the disease. But to understand and study this change and progression, it is necessary to have imaging modalities, without these, it is impossible to provide the quantifications of the risk factors associated. By studying imaging modalities, we have also established that ultrasound is the most convenient modality out of the other existing. Further, for risk assessment, the artificial intelligence-based algorithm is recommended to be the best. It is therefore recommended that all these factors be followed to identify and treat the disease at its earliest.

\subsection{A special note on nutrition and monitoring of CVD risk}

We believe that ineffective knowledge about the disease, progression of the atherosclerotic lesion due to bad nutritional habits and ineffective monitoring does not help in targeting the disease as a whole. Our findings and conclusions help the healthcare sector to get a one-stop solution to their problem.

By addressing all these problems, we feel that more and more people can be educated on their condition. The disease initially diagnosed at very late stages can henceforth be identified and treated accordingly. Preventing the disease will save a lot of people and thus would contribute to decreasing its overall global burden by adopting these practices and understanding the link, one has a greater chance to diagnose and treat it before it worsens or becomes life-threatening. We observed that there is very less knowledge about the effects and behavior this disease would show in the presence of COVID-19, therefore our study helps address this link and provides solutions in all environments.

\subsection{Strengths, weaknesses, and future extensions}

This review provided a brief insight into atherosclerosis by providing a multidisciplinary approach to it. To our understanding, no other paper includes or addresses all these aspects altogether, as it requires and involves different fields. It addresses and forms a unique link between atherosclerosis and its causal risk factors that may affect it, leading to the nutritional aspects associated with its progression. The review gives a deep insight into how plaque is formed. It further reviews methods for arterial imaging and the best-suited methods to minimize risks associated. Stratifying risks and talking about treatment, prevention, and discussing these changes might allow it to prevail in the ongoing pandemic. A limitation was that though we have discussed every aspect in much detail, targeting various minute details posed a challenge for us. We feel that as a further extension of this study, we would like to throw more light on the COVID-19 section and provide more recent findings and challenges that one might 
face at this time. Since the imaging component has shown to have a benefit in CVD risk assessment, strong AI tools such as deep learning can be integrated as well [280].

\section{Conclusions}

The role of optimal nutrition is imperative in the management of atherosclerosis. A link between nutrition and lifestyle choices can trace the outcomes of the disease. An emphasis is made on the role of several dietary compounds in plaque progression. We observed that not only disease progression, but also disease regression, medical nutritional therapy, and optimal nutritional strategies proved to be beneficial. When referring to optimal treatment, it is of immense importance that prompt and effective diagnostic methods be included to prevent the disease from worsening. Therefore, for early detection and a cure, ultrasound and AI-based methods can be used to benefit the detection of plaque formation, progression, tissue characterization, and classification. For treating the disease, several compounds can actively reduce the inflammatory response and prevent the oxidation of LDL. Hence, it is concluded that a multidisciplinary approach towards this disease can help in the optimal treatment and a reduction in associated risk factors as well.

\section{Author contributions}

SmM, ADJ, PA, NNK, LS, JSS contributed in conception and design, SM, ADJ, PA, and JSS contributed manuscript writing, GF, IMS, PSC, MT, KV, SoM, GDK contributed in administrative support and critical evaluation, and all other authors provided vascular inputs, and proofread and approved the manuscript.

\section{Ethics approval and consent to participate}

Not applicable.

\section{Acknowledgment}

Not applicable.

\section{Funding}

This research received no external funding.

\section{Conflict of interest}

The authors declare no conflict of interest.

\section{References}

[1] World Health Organization. Cardiovascular diseases (CVDs): Key facts by WHO May 2016. 2017. Available at: https://www.who.int/news-room/fact-sheets/detail/cardiov ascular-diseases-(cvds) (Accessed: 1 January 2021).

[2] Libby P. Vascular biology of atherosclerosis: overview and state of the art. The American Journal of Cardiology. 2003; 91: 3A$6 \mathrm{~A}$.

[3] Libby P, Ridker PM, Hansson GK. Progress and challenges in translating the biology of atherosclerosis. Nature. 2011; 473: 317-325.

[4] Suri JS, Kathuria C, Molinari F (eds). Atherosclerosis disease management. Springer Science \& Business Media: New York. 2010.

[5] Naghavi M, Libby P, Falk E, Casscells SW, Litovsky S, Rumberger J, et al. From Vulnerable Plaque to Vulnerable Patient: a call for new definitions and risk assessment strategies: Part I. Circulation. 2003; 108: 1664-1672.

[6] Katakami N. Mechanism of Development of Atherosclerosis and Cardiovascular Disease in Diabetes Mellitus. Journal of Atherosclerosis and Thrombosis. 2017; 25: 27-39.

[7] Poznyak A, Grechko AV, Poggio P, Myasoedova VA, Alfieri V, Orekhov AN. The diabetes mellitus-atherosclerosis connection: The role of lipid and glucose metabolism and chronic inflammation. International Journal of Molecular Sciences. 2020; 21: 1835.

[8] Colwell JA, Lopes-Virella M, Halushka PV. Pathogenesis of atherosclerosis in diabetes mellitus. Diabetes Care. 1981; 4: 121-133.

[9] Merchant AT, Kelemen LE, de Koning L, Lonn E, Vuksan V, Jacobs R, et al. Interrelation of saturated fat, trans fat, alcohol intake, and subclinical atherosclerosis. The American Journal of Clinical Nutrition. 2008; 87: 168-174.

[10] Torres N, Guevara-Cruz M, Velázquez-Villegas LA, Tovar AR. Nutrition and Atherosclerosis. Archives of Medical Research. 2015; 46: 408-426.

[11] McGillicuddy FC, Roche HM. Nutritional status, genetic susceptibility, and insulin resistance-important precedents to atherosclerosis. Molecular Nutrition \& Food Research. 2012; 56: 1173-1184.

[12] Neeland IJ, Ross R, Després J, Matsuzawa Y, Yamashita S, Shai I, et al. Visceral and ectopic fat, atherosclerosis, and cardiometabolic disease: a position statement. The Lancet Diabetes \& Endocrinology. 2019; 7: 715-725.

[13] Machado PP, Steele EM, Levy RB, da Costa Louzada ML, Rangan A, Woods J, et al. Ultra-processed food consumption and obesity in the Australian adult population. Nutrition \& Diabetes. 2020; 10: 39.

[14] Queiroz M, Sena CM. Perivascular adipose tissue in age-related vascular disease. Ageing Research Reviews. 2020; 59: 101040.

[15] Logan JG, Kang H, Kim S, Duprez D, Kwon Y, Jacobs DR, et al. Association of obesity with arterial stiffness: the Multi-Ethnic Study of Atherosclerosis (MESA). Vascular Medicine. 2020; 25: 309-318.

[16] Ahmadieh S, Kim H, Weintraub N. Potential role of perivascular adipose tissue in modulating atherosclerosis. Clinical Science. 2020; 134: 3-13.

[17] Sánchez E, Sánchez M, Betriu À, Rius F, Torres G, Purroy F, et al. Are Obesity Indices Useful for Detecting Subclinical Atheromatosis in a Middle-Aged Population? Obesity Facts. 2020; 13: 29-39.

[18] McPhee PG, Singh S, Morrison KM. Childhood obesity and cardiovascular disease risk: working towards solutions. Canadian Journal of Cardiology. 2020; 36: 1352-1361.

[19] Murray CJ. Health effects of dietary risks in 195 countries, 1990-2017: a systematic analysis forthe Global Burden of Disease Study. Lancet. 2019; 393: 1958-1972.

[20] Montero-Salazar H, Donat-Vargas C, Moreno-Franco B, Sandoval-Insausti $\mathrm{H}$, Civeira F, Laclaustra M, et al. High consumption of ultra-processed food may double the risk of 
subclinical coronary atherosclerosis: the Aragon Workers' Health Study (AWHS). BMC Medicine. 2020; 18: 235.

[21] Moore LV, Diez Roux AV, Nettleton JA, Jacobs DR, Franco M. Fast-Food Consumption, Diet Quality, and Neighborhood Exposure to Fast Food: the Multi-Ethnic Study of Atherosclerosis. American Journal of Epidemiology. 2009; 170: 29-36.

[22] Ghosh SS, Righi S, Krieg R, Kang L, Carl D, Wang J, et al. High Fat High Cholesterol Diet (Western Diet) Aggravates Atherosclerosis, Hyperglycemia and Renal Failure in Nephrectomized LDL Receptor Knockout Mice: Role of Intestine Derived Lipopolysaccharide. PLoS ONE. 2015; 10: e0141109.

[23] Srour B, Fezeu LK, Kesse-Guyot E, Allès B, Méjean C, Andrianasolo RM, et al. Ultra-processed food intake and risk of cardiovascular disease: prospective cohort study (NutriNet-Santé). British Medical Journal. 2019; 365: 11451.

[24] Page IH, Stare FJ, Corcoran AC, Pollack H, Wilkinson CF. Atherosclerosis and the fat content of the diet. Circulation. 1957; 16: $163-178$.

[25] de Oliveira Otto MC, Mozaffarian D, Kromhout D, Bertoni AG, Sibley CT, Jacobs DR, et al. Dietary intake of saturated fat by food source and incident cardiovascular disease: the MultiEthnic Study of Atherosclerosis. The American Journal of Clinical Nutrition. 2012; 96: 397-404.

[26] Chrysant S. A new paradigm in the treatment of the cardiovascular disease continuum: focus on prevention. Hippokratia. 2011; 15: 7

[27] Carbone S, Canada JM, Billingsley HE, Siddiqui MS, Elagizi A, Lavie CJ. Obesity paradox in cardiovascular disease: where do we stand? Vascular Health and Risk Management. 2019; 15: 89-100.

[28] Saba L, Jamthikar A, Gupta D, Khanna NN, Viskovic K, Suri HS, et al. Global perspective on carotid intima-media thickness and plaque: should the current measurement guidelines be revisited? International Angiology. 2019; 38: 451-465.

[29] Arnett DK, Blumenthal RS, Albert MA, Buroker AB, Goldberger ZD, Hahn EJ, et al. 2019 ACC/AHA Guideline on the Primary Prevention of Cardiovascular Disease: Executive Summary: a report of the American College of Cardiology/American Heart Association Task Force on Clinical Practice Guidelines. Journal of the American College of Cardiology. 2019; 74: 1376 1414.

[30] Garg N, Muduli SK, Kapoor A, Tewari S, Kumar S, Khanna R, et al. Comparison of different cardiovascular risk score calculators for cardiovascular risk prediction and guideline recommended statin uses. Indian Heart Journal. 2017; 69: 458-463.

[31] Jamthikar AD, Gupta D, Johri AM, Mantella LE, Saba L, Kolluri $\mathrm{R}$, et al. Low-Cost Office-Based Cardiovascular Risk Stratification Using Machine Learning and Focused Carotid Ultrasound in an Asian-Indian Cohort. Journal of Medical Systems. 2020; 44: 208.

[32] Rosengren A, Hawken S, Ounpuu S, Sliwa K, Zubaid M, Almahmeed WA, et al. Association of psychosocial risk factors with risk of acute myocardial infarction in 11119 cases and 13648 controls from 52 countries (the INTERHEART study): casecontrol study. Lancet. 2004; 364: 953-962.

[33] O’Donnell MJ, Chin SL, Rangarajan S, Xavier D, Liu L, Zhang $\mathrm{H}$, et al. Global and regional effects of potentially modifiable risk factors associated with acute stroke in 32 countries (INTERSTROKE): a case-control study. The Lancet. 2016; 388: 761775.

[34] Liu K, Suri JS, inventors; Koninklijke Philips NV, assignee. Automatic vessel indentification for angiographic screening. United States patent US 6,845,260. 2005 Jan 18

[35] Suri JS. Low-cost preventive screening using carotid ultrasound in patients with diabetes. Frontiers in Bioscience. 2020; 25: 1132-1171.

[36] Molinari F, Liboni W, Giustetto P, Badalamenti S, Suri JS. Automatic computer-based tracings (act) in longitudinal 2-d ultrasound images using different scanners. Journal of Mechanics in
Medicine and Biology. 2009; 09: 481-505.

[37] Saba L, Biswas M, Suri HS, Viskovic K, Laird JR, CuadradoGodia E, et al. Ultrasound-based carotid stenosis measurement and risk stratification in diabetic cohort: a deep learning paradigm. Cardiovascular Diagnosis and Therapy. 2019; 9 : 439-461.

[38] Anand SS, Hawkes C, de Souza RJ, Mente A, Dehghan M, Nugent R, et al. Food Consumption and its Impact on Cardiovascular Disease: Importance of Solutions Focused on the Globalized Food System: a report from the workshop convened by the World Heart Federation. Journal of the American College of Cardiology. 2015; 66: 1590-1614.

[39] Korakas E, Dimitriadis G, Raptis A, Lambadiari V. Dietary composition and cardiovascular risk: a mediator or a bystander? Nutrients. 2018; 10: 1912.

[40] Getz GS, Reardon CA. Nutrition and cardiovascular disease. Arteriosclerosis, Thrombosis, and Vascular Biology. 2007; 27: 2499-2506.

[41] Liu H, Zhuang J, Tang P, Li J, Xiong X, Deng H. The Role of the Gut Microbiota in Coronary Heart Disease. Current Atherosclerosis Reports. 2020; 22: 77.

[42] Suri JS, Puvvula A, Biswas M, Majhail M, Saba L, Faa G, et al. COVID-19 pathways for brain and heart injury in comorbidity patients: a role of medical imaging and artificial intelligencebased COVID severity classification: a review. Computers in Biology and Medicine. 2020; 124: 103960.

[43] Wichmann D, Sperhake J, Lütgehetmann M, Steurer S, Edler C Heinemann A, et al. Autopsy Findings and Venous Thromboembolism in Patients with COVID-19: a prospective cohort study. Annals of Internal Medicine. 2020; 173: 268-277.

[44] Zheng Y, Ma Y, Zhang J, Xie X. COVID-19 and the cardiovascular system. Nature Reviews Cardiology. 2020; 17: 259-260.

[45] Cau R, Bassareo PP, Mannelli L, Suri JS, Saba L. Imaging in COVID-19-related myocardial injury. The International Journal of Cardiovascular Imaging. 2021; 37: 1349-1360.

[46] Suri JS, Puvvula A, Majhail M, Biswas M, Jamthikar AD, Saba L, et al. Integration of cardiovascular risk assessment with COVID-19 using artificial intelligence. Reviews in Cardiovascular Medicine. 2020; 21: 541-560.

[47] Centre for Occupational and Environmental Health-UM: Manchester. 2013.

[48] Cuadrado-Godia E, Jamthikar AD, Gupta D, Khanna NN, Araki T, Maniruzzaman M, et al. Ranking of stroke and cardiovascular risk factors for an optimal risk calculator design: Logistic regression approach. Computers in Biology and Medicine. 2019; 108: 182-195.

[49] Viswanathan V, Puvvula A, Jamthikar AD, Saba L, Johri AM, Kotsis V, et al. Bidirectional link between diabetes mellitus and coronavirus disease 2019 leading to cardiovascular disease: a narrative review. World Journal of Diabetes. 2021; 12: 215-237.

[50] Puvvula A, Jamthikar AD, Gupta D, Khanna NN, Porcu M, Saba $\mathrm{L}$, et al. Morphological Carotid Plaque Area is Associated with Glomerular Filtration Rate: a Study of South Asian Indian Patients with Diabetes and Chronic Kidney Disease. Angiology. 2020; 71: 520-535.

[51] Khanna NN, Jamthikar AD, Gupta D, Piga M, Saba L, Carcassi C, et al. Rheumatoid Arthritis: Atherosclerosis Imaging and Cardiovascular Risk Assessment Using Machine and Deep Learning-Based Tissue Characterization. Current Atherosclerosis Reports. 2019; 21: 7

[52] Yahagi K, Kolodgie FD, Lutter C, Mori H, Romero ME, Finn $\mathrm{AV}$, et al. Pathology of Human Coronary and Carotid Artery Atherosclerosis and Vascular Calcification in Diabetes Mellitus. Arteriosclerosis, Thrombosis, and Vascular Biology. 2017; 37: 191-204.

[53] Alexander RW. Hypertension and the Pathogenesis of Atherosclerosis: oxidative stress and the mediation of arterial inflammatory response: a new perspective. Hypertension. 1995; 25: 155-161. 
[54] Csige I, Ujvárosy D, Szabó Z, Lőrincz I, Paragh G, Harangi M, et al. The Impact of Obesity on the Cardiovascular System. Journal of Diabetes Research. 2018; 2018: 3407306.

[55] Yoo HJ, Choi KM. Adipokines as a novel link between obesity and atherosclerosis. World Journal of Diabetes. 2014; 5: 357363.

[56] Turkbey EB, McClelland RL, Kronmal RA, Burke GL, Bild DE, Tracy RP, et al. The impact of obesity on the left ventricle: the Multi-Ethnic Study of Atherosclerosis (MESA). JACC: Cardiovascular Imaging. 2010; 3: 266-274.

[57] Cortés VA, Barrera F, Nervi F. Pathophysiological connections between gallstone disease, insulin resistance, and obesity. Obesity Reviews. 2020; 21: e12983.

[58] McGill HC, McMahan CA, Herderick EE, Zieske AW, Malcom GT, Tracy RE, et al. Obesity accelerates the progression of coronary atherosclerosis in young men. Circulation. 2002; 105: 2712-2718.

[59] Zyriax B, Lau K, Klähn T, Boeing H, Völzke H, Windler E. Association between alcohol consumption and carotid intimamedia thickness in a healthy population: data of the STRATEGY study (Stress, Atherosclerosis and ECG Study). European Journal of Clinical Nutrition. 2010; 64: 1199-1206.

[60] Chiva-Blanch G, Badimon L. Benefits and risks of moderate alcohol consumption on cardiovascular disease: Current findings and controversies. Nutrients. 2020; 12: 108.

[61] Rao Ch S, Subash Y E. The effect of chronic tobacco smoking and chewing on the lipid profile. Journal of Clinical and Diagnostic Research. 2013; 7: 31-34.

[62] Leone A. How and why chemicals from tobacco smoke can induce a rise in blood pressure. World Journal of Pharmacology. 2012; 1: 10-20.

[63] Rahman MM, Laher I. Structural and functional alteration of blood vessels caused by cigarette smoking: an overview of molecular mechanisms. Current Vascular Pharmacology. 2007; 5: 276-292.

[64] Virdis A, Giannarelli C, Neves MF, Taddei S, Ghiadoni L. Cigarette smoking and hypertension. Current Pharmaceutical Design. 2010; 16: 2518-2525.

[65] Morris AA, Ko Y, Hutcheson SH, Quyyumi A. Race/Ethnic and Sex Differences in the Association of Atherosclerotic Cardiovascular Disease Risk and Healthy Lifestyle Behaviors. Journal of the American Heart Association. 2018; 7: e008250.

[66] Wildman RP, Schott LL, Brockwell S, Kuller LH, SuttonTyrrell K. A dietary and exercise intervention slows menopauseassociated progression of subclinical atherosclerosis as measured by intima-media thickness of the carotid arteries. Journal of the American College of Cardiology. 2004; 44: 579-585.

[67] Aronson D, Rayfield EJ. How hyperglycemia promotes atherosclerosis: molecular mechanisms. Cardiovascular Diabetology. 2002; 1: 1-10.

[68] Olechnowicz-Tietz S, Gluba A, Paradowska A, Banach M, Rysz $\mathrm{J}$. The risk of atherosclerosis in patients with chronic kidney disease. International Urology and Nephrology. 2013; 45: 16051612.

[69] Kon V, Linton MF, Fazio S. Atherosclerosis in chronic kidney disease: the role of macrophages. Nature Reviews. Nephrology. 2011; 7: 45-54

[70] Khanna NN, Jamthikar AD, Gupta D, Araki T, Piga M, Saba L, et al. Effect of carotid image-based phenotypes on cardiovascular risk calculator: AECRS1.0. Medical \& Biological Engineering \& Computing. 2019; 57: 1553-1566.

[71] Kahlenberg JM, Kaplan MJ. Mechanisms of premature atherosclerosis in rheumatoid arthritis and lupus. Annual Review of Medicine. 2013; 64: 249-263.

[72] Ganguly P, Alam SF. Role of homocysteine in the development of cardiovascular disease. Nutrition Journal. 2015; 14: 6.

[73] Talayero BG, Sacks FM. The role of triglycerides in atherosclerosis. Current Cardiology Reports. 2012; 13: 544-552.

[74] Pearson GJ, Thanassoulis G, Anderson TJ, Barry AR, Couture
P, Dayan N, et al. 2021 Canadian Cardiovascular Society Guidelines for the Management of Dyslipidemia for the Prevention of Cardiovascular Disease in the Adult. Canadian Journal of Cardiology. 2021; 37: 1129-1150.

[75] Slevin M, Iemma RS, Zeinolabediny Y, Liu D, Ferris GR, Caprio $\mathrm{V}$, et al. Acetylcholine Inhibits Monomeric C-Reactive Protein Induced Inflammation, Endothelial Cell Adhesion, and Platelet Aggregation; a Potential Therapeutic? Frontiers in Immunology. 2018; 9: 2124.

[76] Badimon L, Peña E, Arderiu G, Padró T, Slevin M, Vilahur G, et al. C-Reactive Protein in Atherothrombosis and Angiogenesis. Frontiers in Immunology. 2018; 9: 430.

[77] Iqbal MP. Trans fatty acids - a risk factor for cardiovascular disease. Pakistan Journal of Medical Sciences. 2014; 30: 194-197.

[78] DD Z. Trans fatty acids and atherosclerosis-effects on inflammation and endothelial function. Nutrition \& Food Sciences. 2015; 5: 6.

[79] Chen C, Tetri LH, Neuschwander-Tetri BA, Huang SS, Huang JS. A mechanism by which dietary trans fats cause atherosclerosis. The Journal of Nutritional Biochemistry. 2011; 22: 649 655.

[80] Feingold KR, Grunfeld C. Introduction to lipids and lipoproteins. MDText, Inc.: South Dartmouth (MA), 07 Aug 2015.

[81] Ginsberg HN. Lipoprotein physiology. Endocrinology and Metabolism Clinics of North America. 1998; 27: 503-519.

[82] Chroni A, Leondaritis G, Karlsson H. Lipids and lipoproteins in atherosclerosis. Journal of Lipids. 2011; 2011: 160104.

[83] Singh IM, Shishehbor MH, Ansell BJ. High-density lipoprotein as a therapeutic target: a systematic review. Journal of the American Medical Association. 2007; 298: 786-798.

[84] Tomkin GH, Owens D. The chylomicron: relationship to atherosclerosis. International Journal of Vascular Medicine. 2012; 2012: 784536.

[85] Olofsson S, Borèn J. Apolipoprotein B: a clinically important apolipoprotein which assembles atherogenic lipoproteins and promotes the development of atherosclerosis. Journal of Internal Medicine. 2005; 258: 395-410.

[86] Ahmadi A, Leipsic J, Blankstein R, Taylor C, Hecht H, Stone $\mathrm{GW}$, et al. Do plaques rapidly progress prior to myocardial infarction? the interplay between plaque vulnerability and progression. Circulation Research. 2015; 117: 99-104.

[87] Kim YR, Han KH. Familial hypercholesterolemia and the atherosclerotic disease. Korean Circulation Journal. 2013; 43 363-367.

[88] Mohebi-Nejad A, Bikdeli B. Omega-3 supplements and cardiovascular diseases. Tanaffos. 2014; 13: 6 .

[89] Calder PC. The role of marine omega-3 (n-3) fatty acids in inflammatory processes, atherosclerosis and plaque stability. Molecular Nutrition \& Food Research. 2012; 56: 1073-1080.

[90] Bäck M. Omega-3 fatty acids in atherosclerosis and coronary artery disease. Future Science OA. 2017; 3: FSO236.

[91] Spence JD, Jenkins DJA, Davignon J. Egg yolk consumption and carotid plaque. Atherosclerosis. 2012; 224: 469-473.

[92] David Spence J. Dietary cholesterol and egg yolk should be avoided by patients at risk of vascular disease. Journal of Translational Internal Medicine. 2016; 4: 20-24.

[93] Brown JM, Hazen SL. The gut microbial endocrine organ: bacterially derived signals driving cardiometabolic diseases. Annual Review of Medicine. 2015; 66: 343-359.

[94] Randrianarisoa E, Lehn-Stefan A, Wang X, Hoene M, Peter A Heinzmann SS, et al. Relationship of Serum Trimethylamine NOxide (TMAO) Levels with early Atherosclerosis in Humans. Scientific Reports. 2016; 6: 26745.

[95] Wang Z, Roberts A, Buffa J, Levison B, Zhu W, Org E, et $a l$. Non-lethal Inhibition of Gut Microbial Trimethylamine Production for the Treatment of Atherosclerosis. Cell. 2015; 163: 1585-1595.

[96] Koeth RA, Wang Z, Levison BS, Buffa JA, Org E, Sheehy BT, et al. Intestinal microbiota metabolism of L-carnitine, a nutrient 
in red meat, promotes atherosclerosis. Nature Medicine. 2013; 19: $576-585$

[97] Li XS, Obeid S, Klingenberg R, Gencer B, Mach F, Räber L, et al. Gut microbiota-dependent trimethylamine $\mathrm{N}$-oxide in acute coronary syndromes: a prognostic marker for incident cardiovascular events beyond traditional risk factors. European Heart Journal. 2017; 38: 814-824.

[98] Wang Z, Klipfell E, Bennett BJ, Koeth R, Levison BS, Dugar $\mathrm{B}$, et al. Gut flora metabolism of phosphatidylcholine promotes cardiovascular disease. Nature. 2011; 472: 57-63.

[99] Tang WHW, Wang Z, Levison BS, Koeth RA, Britt EB, Fu X, et al. Intestinal microbial metabolism of phosphatidylcholine and cardiovascular risk. The New England Journal of Medicine. 2013; 368: 1575-1584.

[100] Sun X, Jiao X, Ma Y, Liu Y, Zhang L, He Y, et al. Trimethylamine $\mathrm{N}$-oxide induces inflammation and endothelial dysfunction in human umbilical vein endothelial cells via activating ROS-TXNIP-NLRP3 inflammasome. Biochemical and Biophysical Research Communications. 2016; 481: 63-70.

[101] Natural history of aortic and coronary atherosclerotic lesions in youth: findings from the PDAY study. Pathobiological Determinants of Atherosclerosis in Youth (PDAY) Research Group. Arteriosclerosis, Thrombosis, and Vascular Biology. 1993; 13: 1291-1298.

[102] Strong JP, Malcom GT, McMahan CA, Tracy RE, Newman WP, Herderick EE, et al. Prevalence and extent of atherosclerosis in adolescents and young adults: implications for prevention from the Pathobiological Determinants of Atherosclerosis in Youth Study. Journal of the American Medical Association. 1999; 281: 727-735.

[103] Tabas I, Williams KJ, Borén J. Subendothelial Lipoprotein Retention as the Initiating Process in Atherosclerosis: update and therapeutic implications. Circulation. 2007; 116: 1832-1844.

[104] Catapano AL, Maggi FM, Tragni E. Low density lipoprotein oxidation, antioxidants, and atherosclerosis. Current Opinion in Cardiology. 2000; 15: 355-363.

[105] Linton MF, Yancey PG, Davies SS, Jerome WG, Linton EF, Song WL, et al. The role of lipids and lipoproteins in atherosclerosis. In: Feingold KR, Anawalt B, Boyce A, Chrousos G, de Herder WW, Dhatariya K, (eds) Endotext [Internet]. MDText.com, Inc.: South Dartmouth (MA). 2019.

[106] Insull W. The pathology of atherosclerosis: plaque development and plaque responses to medical treatment. The American Journal of Medicine. 2009; 122: S3-S14.

[107] Xu J, Lu X, Shi G. Vasa vasorum in atherosclerosis and clinical significance. International Journal of Molecular Sciences. 2015; 16: 11574-11608.

[108] Keaney JF. Atherosclerosis: from lesion formation to plaque activation and endothelial dysfunction. Molecular Aspects of Medicine. 2000; 21: 99-166.

[109] Narula J, Nakano M, Virmani R, Kolodgie FD, Petersen R, Newcomb R, et al. Histopathologic characteristics of atherosclerotic coronary disease and implications of the findings for the invasive and noninvasive detection of vulnerable plaques. Journal of the American College of Cardiology. 2013; 61: 1041-1051.

[110] Sukhorukov VN, Khotina VA, Chegodaev YS, Ivanova E, Sobenin IA, Orekhov AN. Lipid metabolism in macrophages: Focus on atherosclerosis. Biomedicines. 2020; 8: 262.

[111] Fanni D, Gerosa C, Nurchi VM, Suri JS, Nardi V, Congiu T, et al. Trace elements and the carotid plaque: the GOOD (Mg, $\mathrm{Zn}$, Se), the UGLY (Fe, $\mathrm{Cu})$, and the BAD (P, Ca)? European Review for Medical and Pharmacological Sciences. 2021; 25: 3772-3790.

[112] Massberg S, Brand K, Grüner S, Page S, Müller E, Müller I, et al. A critical role of platelet adhesion in the initiation of atherosclerotic lesion formation. The Journal of Experimental Medicine. 2002; 196: 887-896.

[113] Johnson KM, Dowe DA, Brink JA. Traditional Clinical Risk Assessment Tools do not Accurately Predict Coronary
Atherosclerotic Plaque Burden: a CT Angiography Study American Journal of Roentgenology. 2009; 192: 235-243.

[114] Pen A, Yam Y, Chen L, Dennie C, McPherson R, Chow BJW. Discordance between Framingham Risk Score and atherosclerotic plaque burden. European Heart Journal. 2013; 34: 10751082.

[115] Go AS, Mozaffarian D, Roger VL, Benjamin EJ, Berry JD, Blaha MJ, et al. Heart disease and stroke statistics-2014 update: a report from the American Heart Association. Circulation. 2014; 129: e28-e292.

[116] Cheng IT, Wong KT, Li EK, Wong PCH, Lai BT, Yim IC, et al. Comparison of carotid artery ultrasound and Framingham risk score for discriminating coronary artery disease in patients with psoriatic arthritis. RMD Open. 2020; 6: e001364.

[117] Hirata T, Arai Y, Takayama M, Abe Y, Ohkuma K, Takebayashi T. Carotid Plaque Score and Risk of Cardiovascular Mortality in the Oldest Old: Results from the TOOTH Study. Journal of Atherosclerosis and Thrombosis. 2018; 25: 55-64.

[118] Skeoch S, Cristinacce PLH, Williams H, Pemberton P, Xu D, Sun J, et al. Imaging atherosclerosis in rheumatoid arthritis: evidence for increased prevalence, altered phenotype and a link between systemic and localised plaque inflammation. Scientific Reports. 2017; 7: 827.

[119] Kramer CM, Anderson JD. MRI of atherosclerosis: diagnosis and monitoring therapy. Expert Review of Cardiovascular Therapy. 2007; 5: 69-80.

[120] Yuan C, Kerwin WS. MRI of atherosclerosis. Journal of Magnetic Resonance Imaging. 2004; 19: 710-719.

[121] Koelemay MJW, Nederkoorn PJ, Reitsma JB, Majoie CB. Systematic review of computed tomographic angiography for assessment of carotid artery disease. Stroke. 2004; 35: 2306-2312.

[122] Boi A, Jamthikar AD, Saba L, Gupta D, Sharma A, Loi B, et al. A Survey on Coronary Atherosclerotic Plaque Tissue Characterization in Intravascular Optical Coherence Tomography. Current Atherosclerosis Reports. 2018; 20: 33.

[123] Jamthikar A, Gupta D, Khanna NN, Araki T, Saba L, Nicolaides A, et al. A Special Report on Changing Trends in Preventive Stroke/Cardiovascular Risk Assessment via B-Mode Ultrasonography. Current Atherosclerosis Reports. 2019; 21: 25.

[124] Laine A, Sanches JM, Suri JS. Ultrasound Imaging: Advances and Applications. Springer: New York. 2012.

[125] Beach KW. Principles of Ultrasonic Imaging and Instrumentation. Ultrasound and Carotid Bifurcation Atherosclerosis. In A. Nicolaides, K. W. Beach, E. Kyriacou\&C. S. Pattichis (eds) Springer London: London. 2012.

[126] Saba L, Acharya UR, Guerriero S, Suri JS. Ovarian Neoplasm Imaging. Springer Science \& Business Media: New York. 2014.

[127] Kotsis V, Jamthikar AD, Araki T, Gupta D, Laird JR, Giannopoulos AA, et al. Echolucency-based phenotype in carotid atherosclerosis disease for risk stratification of diabetes patients. Diabetes Research and Clinical Practice. 2018; 143: 322-331.

[128] Khanna NN, Jamthikar AD, Gupta D, Nicolaides A, Araki T, Saba L, et al. Performance evaluation of 10-year ultrasound image-based stroke/cardiovascular (CV) risk calculator by comparing against ten conventional CV risk calculators: a diabetic study. Computers in Biology and Medicine. 2019; 105: 125143.

[129] Khanna NN, Jamthikar AD, Araki T, Gupta D, Piga M, Saba $\mathrm{L}$, et al. Nonlinear model for the carotid artery disease 10 -year risk prediction by fusing conventional cardiovascular factors to carotid ultrasound image phenotypes: a Japanese diabetes cohort study. Echocardiography. 2019; 36: 345-361.

[130] Jamthikar A, Gupta D, Khanna NN, Saba L, Araki T, Viskovic $\mathrm{K}$, et al. A low-cost machine learning-based cardiovascular/stroke risk assessment system: integration of conventional factors with image phenotypes. Cardiovascular Diagnosis and Therapy. 2019; 9: 420-430.

[131] Molinari F, Zeng G, Suri JS. Intima-media thickness: setting a standard for a completely automated method of ultrasound mea- 
surement. IEEE Transactions on Ultrasonics, Ferroelectrics, and Frequency Control. 2010; 57: 1112-1124.

[132] Molinari F, Pattichis CS, Zeng G, Saba L, Acharya UR, Sanfilippo R, et al. Completely automated multiresolution edge snapper-a new technique for an accurate carotid ultrasound IMT measurement: clinical validation and benchmarking on a multiinstitutional database. IEEE Transactions on Image Processing : a Publication of the IEEE Signal Processing Society. 2011; 21: 1211-1222.

[133] Molinari F, Rajendra Acharya U, Zeng G, Meiburger KM, Suri JS. Completely automated robust edge snapper for carotid ultrasound IMT measurement on a multi-institutional database of 300 images. Medical \& Biological Engineering \& Computing. 2011; 49: 935-945.

[134] Molinari F, Meiburger KM, Zeng G, Acharya UR, Liboni W, Nicolaides A, et al. Carotid artery recognition system: a comparison of three automated paradigms for ultrasound images. Medical Physics. 2012; 39: 378-391.

[135] Saba L, Montisci R, Molinari F, Tallapally N, Zeng G, Mallarini G, et al. Comparison between manual and automated analysis for the quantification of carotid wall by using sonography. A validation study with CT. European Journal of Radiology. 2012; 81: 911-918.

[136] Molinari F, Meiburger KM, Saba L, Acharya UR, Ledda G, Zeng G, et al. Ultrasound IMT measurement on a multi-ethnic and multi-institutional database: our review and experience using four fully automated and one semi-automated methods. Computer Methods and Programs in Biomedicine. 2012; 108: 946-960.

[137] Ikeda N, Gupta A, Dey N, Bose S, Shafique S, Arak T, et al. Improved correlation between carotid and coronary atherosclerosis SYNTAX score using automated ultrasound carotid bulb plaque IMT measurement. Ultrasound in Medicine \& Biology. 2015; 41: 1247-1262.

[138] Saba L, Meiburger KM, Molinari F, Ledda G, Anzidei M, Acharya UR, et al. Carotid IMT variability (IMTV) and its validation in symptomatic versus asymptomatic Italian population: can this be a useful index for studying symptomaticity? Echocardiography. 2012; 29: 1111-1119.

[139] Johri AM, Lajkosz KA, Grubic N, Islam S, Li TY, Simpson $\mathrm{CS}$, et al. Maximum plaque height in carotid ultrasound predicts cardiovascular disease outcomes: a population-based validation study of the American society of echocardiography's grade II-III plaque characterization and protocol. The International Journal of Cardiovascular Imaging. 2021; 37: 1601-1610.

[140] Jamthikar AD, Gupta D, Mantella LE, Saba L, Laird JR, Johri $\mathrm{AM}$, et al. Multiclass machine learning vs. conventional calculators for stroke/CVD risk assessment using carotid plaque predictors with coronary angiography scores as gold standard: a 500 participants study. The International Journal of Cardiovascular Imaging. 2020; 37: 1171-1187.

[141] Mantella LE, Colledanchise KN, Hétu M, Feinstein SB, Abunassar J, Johri AM. Carotid intraplaque neovascularization predicts coronary artery disease and cardiovascular events. European Heart Journal - Cardiovascular Imaging. 2019; 20: 12391247.

[142] Hansen K, Östling G, Persson M, Nilsson PM, Melander O, Engström G, et al. The effect of smoking on carotid intima-media thickness progression rate and rate of lumen diameter reduction. European Journal of Internal Medicine. 2016; 28: 74-79.

[143] Rashid SA, Mahmud SA. Correlation between Carotid Artery Intima-Media Thickness and Luminal Diameter with Body Mass Index and other Cardiovascular Risk Factors in Adults. Sultan Qaboos University Medical Journal. 2015; 15: e344-e350.

[144] Johnson HM, Douglas PS, Srinivasan SR, Bond MG, Tang R, $\mathrm{Li} \mathrm{S}$, et al. Predictors of carotid intima-media thickness progression in young adults: the Bogalusa Heart Study. Stroke. 2007; 38: 900-905.

[145] Lind M, Pivodic A, Cea-Soriano L, Nerman O, Pehrsson
N, Garcia-Rodriguez LA. Changes in HbA1c and frequency of measuring HbA1c and adjusting glucose-lowering medications in the 10 years following diagnosis of type 2 diabetes: a population-based study in the UK. Diabetologia. 2014; 57: 1586-1594.

[146] Rosvall M, Persson M, Östling G, Nilsson PM, Melander O, Hedblad B, et al. Risk factors for the progression of carotid intima-media thickness over a 16-year follow-up period: the Malmö Diet and Cancer Study. Atherosclerosis. 2015; 239: 615-621.

[147] Yang C, Lin T, Liu C, Chen Y, Tang S, Yang J, et al. Eating right for a healthier heart: Food choice contributes to cardiometabolic benefits and reduction of carotid intima-media thickness. Nutrition. 2020; 78: 110892.

[148] Johansson A, Acosta S. Diet and Lifestyle as Risk Factors for Carotid Artery Disease: a Prospective Cohort Study. Cerebrovascular Diseases. 2020; 49: 563-569.

[149] Wang D, Karvonen-Gutierrez CA, Jackson EA, Elliott MR, Appelhans BM, Barinas-Mitchell E, et al. Western Dietary Pattern Derived by Multiple Statistical Methods is Prospectively Associated with Subclinical Carotid Atherosclerosis in Midlife Women. The Journal of Nutrition. 2020; 150: 579-591.

[150] Petersen KS, Clifton PM, Keogh JB. The association between carotid intima media thickness and individual dietary components and patterns. Nutrition, Metabolism, and Cardiovascular Diseases. 2014; 24: 495-502.

[151] Murie-Fernandez M, Irimia P, Toledo E, Martínez-Vila E, BuilCosiales P, Serrano-Martínez M, et al. Carotid intima-media thickness changes with Mediterranean diet: a randomized trial (PREDIMED-Navarra). Atherosclerosis. 2011; 219: 158-162.

[152] Gardener H, Wright CB, Cabral D, Scarmeas N, Gu Y, Cheung $\mathrm{K}$, et al. Mediterranean diet and carotid atherosclerosis in the Northern Manhattan Study. Atherosclerosis. 2014; 234: 303310.

[153] Sala-Vila A, Romero-Mamani E, Gilabert R, Núñez I, de la Torre R, Corella D, et al. Changes in ultrasound-assessed carotid intima-media thickness and plaque with a Mediterranean diet: a substudy of the PREDIMED trial. Arteriosclerosis, Thrombosis, and Vascular Biology. 2014; 34: 439-445.

[154] Petersen KS, Keogh JB, Lister NB, Clifton PM. Dietary quality and carotid intima media thickness in type 1 and type 2 diabetes: Follow-up of a randomised controlled trial. Nutrition, Metabolism, and Cardiovascular Diseases. 2018; 28: 830-838.

[155] Chiavaroli L, Mirrahimi A, Ireland C, Mitchell S, SahyePudaruth S, Coveney J, et al. Cross-sectional associations between dietary intake and carotid intima media thickness in type 2 diabetes: baseline data from a randomised trial. BMJ Open. 2017; 7: e015026.

[156] Shai I, Spence JD, Schwarzfuchs D, Henkin Y, Parraga G, Rudich A, et al. Dietary intervention to reverse carotid atherosclerosis. Circulation. 2010; 121: 1200-1208.

[157] Mahe G, Ronziere T, Laviolle B, Golfier V, Cochery T, De Bray J, et al. An unfavorable dietary pattern is associated with symptomatic ischemic stroke and carotid atherosclerosis. Journal of Vascular Surgery. 2010; 52: 62-68.

[158] Recio-Rodriguez JI, Garcia-Yu IA, Alonso-Dominguez R, Maderuelo-Fernandez JA, Patino-Alonso MC, Agudo-Conde C, et al. Diet quality and carotid atherosclerosis in intermediate cardiovascular risk individuals. Nutrition Journal. 2017; 16: 40.

[159] Acharya UR, Sree SV, Muthu Rama Krishnan M, Krishnananda N, Ranjan S, Umesh P, et al. Automated classification of patients with coronary artery disease using grayscale features from left ventricle echocardiographic images. Computer Methods and Programs in Biomedicine. 2013; 112: 624-632.

[160] Pearson TA, Blair SN, Daniels SR, Eckel RH, Fair JM, Fortmann SP, et al. AHA Guidelines for Primary Prevention of Cardiovascular Disease and Stroke: 2002 Update: consensus panel guide to comprehensive risk reduction for adult patients without coronary or other atherosclerotic vascular diseases. Circulation. 
2002; 106: 388-391.

[161] Rabar S, Harker M, O’Flynn N, Wierzbicki AS. Lipid modification and cardiovascular risk assessment for the primary and secondary prevention of cardiovascular disease: summary of updated NICE guidance. British Medical Journal. 2008; 349: g4356.

[162] World Health Organization. Package of essential noncommunicable (PEN) disease interventions for primary health care in lowresource settings. 2010. Available at: https://www.who.int/nmh/ publications/essential_ncd_interventions $\backslash$ _lr_settings.pdf (Accessed: 1 April 2021).

[163] Goff DC, Lloyd-Jones DM, Bennett G, Coady S, D’Agostino RB, Gibbons R, et al. 2013 ACC/AHA Guideline on the Assessment of Cardiovascular Risk: a report of the American College of Cardiology/American Heart Association Task Force on Practice Guidelines. Journal of the American College of Cardiology. 2014; 63: 2935-2959.

[164] Lalor E, Boyden A, Cadilhac D, Colagiur S, Doust J, Fraser D, et al. Guidelines for the management of absolute cardiovascular disease risk. 2012. Avaialable at: https://espace.library.uq.edu. au/view/UQ:340868 (Accessed: 1 April 2021).

[165] Reiner Z, Catapano AL, De Backer G, Graham I, Taskinen M, Wiklund O, et al. ESC/EAS Guidelines for the management of dyslipidaemias: the Task Force for the management of dyslipidaemias of the European Society of Cardiology (ESC) and the European Atherosclerosis Society (EAS). European Heart Journal. 2011; 32: 1769-1818.

[166] Lin E, Alessio A. What are the basic concepts of temporal, contrast, and spatial resolution in cardiac CT? Journal of Cardiovascular Computed Tomography. 2009; 3: 403-408.

[167] Bibbins-Domingo K, Grossman DC, Curry SJ, Davidson KW, Epling JW, García FAR, et al. Statin Use for the Primary Prevention of Cardiovascular Disease in Adults: us Preventive Services Task Force Recommendation Statement. Journal of the American Medical Association. 2016; 316: 1997-2007.

[168] Curry SJ, Krist AH, Owens DK, Barry MJ, Caughey AB, Davidson KW, et al. Screening for Cardiovascular Disease Risk with Electrocardiography: US Preventive Services Task Force Recommendation Statement. Journal of the American Medical Association. 2018; 319: 2308-2314.

[169] D’Agostino RB, Vasan RS, Pencina MJ, Wolf PA, Cobain M, Massaro JM, et al. General Cardiovascular Risk Profile for Use in Primary Care. Circulation. 2008; 117: 743-753.

[170] Ridker PM, Paynter NP, Rifai N, Gaziano JM, Cook NR. Creactive protein and parental history improve global cardiovascular risk prediction: the Reynolds Risk Score for men. Circulation. 2008; 118: 2243-2251, 4p following 2251.

[171] Ridker PM, Buring JE, Rifai N, Cook NR. Development and validation of improved algorithms for the assessment of global cardiovascular risk in women: the Reynolds Risk Score. Journal of the American Medical Association. 2007; 297: 611-619.

[172] Conroy RM, Pyörälä K, Fitzgerald AP, Sans S, Menotti A, De Backer G, et al. Estimation of ten-year risk of fatal cardiovascular disease in Europe: the SCORE project. European Heart Journal. 2003; 24: 987-1003.

[173] Hippisley-Cox J, Coupland C, Brindle P. Development and validation of QRISK3 risk prediction algorithms to estimate future risk of cardiovascular disease: prospective cohort study. British Medical Journal. 2017; 357: j2099.

[174] Hippisley-Cox J, Coupland C, Vinogradova Y, Robson J, Minhas R, Sheikh A, et al. Predicting cardiovascular risk in England and Wales: prospective derivation and validation of QRISK2. British Medical Journal. 2008; 336: 1475-1482.

[175] Anderson TJ, Grégoire J, Pearson GJ, Barry AR, Couture P, Dawes M, et al. 2016 Canadian Cardiovascular Society Guidelines for the Management of Dyslipidemia for the Prevention of Cardiovascular Disease in the Adult. The Canadian Journal of Cardiology. 2016; 32: 1263-1282.

[176] Bosomworth NJ. Practical use of the Framingham risk score in primary prevention: Canadian perspective. Canadian Family Physician Medecin De Famille Canadien. 2011; 57: 417-423.

[177] Duerden M, O’Flynn N, Qureshi N. Cardiovascular risk assessment and lipid modification: NICE guideline. the British Journal of General Practice. 2015; 65: 378-380.

[178] NICE. Cardiovascular disease: risk assessment and reduction, including lipid modifification. 2014. Available at: https://www nice.org.uk/guidance/cg181 (Accessed: 1 May 2021).

[179] Cooper A, O’Flynn N. Risk assessment and lipid modification for primary and secondary prevention of cardiovascular disease: summary of NICE guidance. British Medical Journal. 2008; 336: 1246-1248.

[180] Viswanathan V, Jamthikar AD, Gupta D, Puvvula A, Khanna $\mathrm{NN}$, Saba L, et al. Integration of estimated glomerular filtration rate biomarker in image-based cardiovascular disease/stroke risk calculator: a south Asian-Indian diabetes cohort with moderate chronic kidney disease. International Angiology. 2020; 39: 290306.

[181] Viswanathan V, Jamthikar AD, Gupta D, Puvvula A, Khanna NN, Saba L, et al. Does the Carotid Bulb Offer a Better 10Year CVD/Stroke Risk Assessment Compared to the Common Carotid Artery? A 1516 Ultrasound Scan Study. Angiology. 2020; 71: 920-933.

[182] Jamthikar AD, Puvvula A, Gupta D, Johri AM, Nambi V, Khanna NN, et al. Cardiovascular disease and stroke risk assessment in patients with chronic kidney disease using integration of estimated glomerular filtration rate, ultrasonic image phenotypes, and artificial intelligence: a narrative review. International Angiology. 2020; 40: 150-164.

[183] Jamthikar AD, Gupta D, Puvvula A, Johri AM, Khanna NN, Saba L, et al. Cardiovascular risk assessment in patients with rheumatoid arthritis using carotid ultrasound B-mode imaging. Rheumatology International. 2020; 40: 1921-1939.

[184] Kakadiaris IA, Vrigkas M, Yen AA, Kuznetsova T, Budoff M, Naghavi M. Machine Learning Outperforms ACC/AHA CVD Risk Calculator in MESA. Journal of the American Heart Association. 2018; 7: e0174944.

[185] Weng SF, Reps J, Kai J, Garibaldi JM, Qureshi N. Can machine-learning improve cardiovascular risk prediction using routine clinical data? PLoS ONE. 2017; 12: e0174944.

[186] Jamthikar A, Gupta D, Saba L, Khanna NN, Araki T, Viskovic $\mathrm{K}$, et al. Cardiovascular/stroke risk predictive calculators: a comparison between statistical and machine learning models. Cardiovascular Diagnosis and Therapy. 2020; 10: 919-938.

[187] Jamthikar A, Gupta D, Khanna NN, Saba L, Laird JR, Suri JS. Cardiovascularstroke risk prevention: a new machine learning framework integrating carotid ultrasound image-based phenotypes and its harmonics with conventional risk factors. Indian Heart Journal. 2020; 72: 258-264.

[188] Jamthikar AD, Gupta D, Saba L, Khanna NN, Viskovic K, Mavrogeni S, et al. Artificial intelligence framework for predictive cardiovascular and stroke risk assessment models: a narrative review of integrated approaches using carotid ultrasound. Computers in Biology and Medicine. 2020; 126: 104043.

[189] Acharya UR, Swapna G, Sree SV, Molinari F, Gupta S, Bardales RH, et al. A review on ultrasound-based thyroid cancer tissue characterization and automated classification. Technology in Cancer Research \& Treatment. 2014; 13: 289-301.

[190] Molinari F, Mantovani A, Deandrea M, Limone P, Garberoglio R, Suri JS. Characterization of single thyroid nodules by contrast-enhanced 3-D ultrasound. Ultrasound in Medicine \& Biology. 2010; 36: 1616-1625.

[191] Martis RJ, Acharya UR, Prasad H, Chua CK, Lim CM, Suri JS. Application of higher order statistics for atrial arrhythmia classification. Biomedical Signal Processing and Control. 2013; 8: 888-900.

[192] Acharya UR, Sree SV, Ribeiro R, Krishnamurthi G, Marinho RT, Sanches J, et al. Data mining framework for fatty liver disease classification in ultrasound: a hybrid feature extraction 
paradigm. Medical Physics. 2012; 39: 4255-4264.

[193] Rajendra Acharya U, Rama Krishnan MM, Vinitha Sree S, Sanches J, Shafique S, Nicolaides A, et al. Plaque Tissue Characterization and Classification in Ultrasound Carotid Scans: a Paradigm for Vascular Feature Amalgamation. IEEE Transactions on Instrumentation and Measurement. 2013; 62: 392-400.

[194] Suri JS. Imaging based symptomatic classification and cardiovascular stroke risk score estimation. United States of America, Patient Number: US20110257545A1. October 20, 2011.

[195] Lekadir K, Galimzianova A, Betriu A, Del Mar Vila M, Igual L, Rubin DL, et al. A Convolutional Neural Network for Automatic Characterization of Plaque Composition in Carotid Ultrasound. IEEE Journal of Biomedical and Health Informatics. 2017; 21: 48-55.

[196] Rigdon J, Basu S. Machine learning with sparse nutrition data to improve cardiovascular mortality risk prediction in the USA using nationally randomly sampled data. BMJ Open. 2019; 9: e032703.

[197] Alaa AM, Bolton T, Di Angelantonio E, Rudd JH, van Der Schaar M. Cardiovascular disease risk prediction using automated machine learning: A prospective study of 423,604 UK Biobank participants. PLoS ONE. 2019; 14: e0213653.

[198] Räsänen M, Niinikoski H, Keskinen S, Helenius H, Talvia S, Rönnemaa T, et al. Parental nutrition knowledge and nutrient intake in an atherosclerosis prevention project: the impact of child-targeted nutrition counselling. Appetite. 2003; 41: 69-77.

[199] Ravera A, Carubelli V, Sciatti E, Bonadei I, Gorga E, Cani D, et al. Nutrition and Cardiovascular Disease: Finding the Perfect Recipe for Cardiovascular Health. Nutrients. 2016; 8: 363.

[200] Yin X, Chen Y, Lu W, Jin T, LI L. Association of dietary patterns with the newly diagnosed diabetes mellitus and central obesity: a community based cross-sectional study. Nutrition \& Diabetes. 2020; 10: 16.

[201] Boban M, Bulj N, Kolačević Zeljković M, Radeljić V, Krcmar $\mathrm{T}$, Trbusic M, et al. Nutritional Considerations of Cardiovascular Diseases and Treatments. Nutrition and Metabolic Insights. 2019; 12: 117863881983370.

[202] Gattone M, Giannuzzi P. Interventional strategies in early atherosclerosis. Monaldi Archives for Chest Disease. 2006; 66: $54-62$.

[203] Shai I, Rosner BA, Shahar DR, Vardi H, Azrad AB, Kanfi A, et al. Dietary evaluation and attenuation of relative risk: multiple comparisons between blood and urinary biomarkers, food frequency, and 24-hour recall questionnaires: the DEARR study. The Journal of Nutrition. 2005; 135: 573-579.

[204] Aquila G, Marracino L, Martino V, Calabria D, Campo G, Caliceti C, et al. The Use of Nutraceuticals to Counteract Atherosclerosis: the Role of the Notch Pathway. Oxidative Medicine and Cellular Longevity. 2019; 2019: 1-30.

[205] Moss JWE, Ramji DP. Nutraceutical therapies for atherosclerosis. Nature Reviews. Cardiology. 2016; 13: 513-532.

[206] Lee JH, O’Keefe JH, Lavie CJ, Marchioli R, Harris WS. Omega-3 Fatty Acids for Cardioprotection. Mayo Clinic Proceedings. 2008; 83: 324-332.

[207] Kris-Etherton PM, Harris WS, Appel LJ. Omega-3 fatty acids and cardiovascular disease: new recommendations from the American Heart Association. Arteriosclerosis, Thrombosis, and Vascular Biology. 2003; 23: 151-152.

[208] Leslie MA, Cohen DJA, Liddle DM, Robinson LE, Ma DWL. A review of the effect of omega-3 polyunsaturated fatty acids on blood triacylglycerol levels in normolipidemic and borderline hyperlipidemic individuals. Lipids in Health and Disease. 2015; 14: 53.

[209] Yagi S, Aihara K, Fukuda D, Takashima A, Hara T, Hotchi J, et al. Effects of docosahexaenoic Acid on the endothelial function in patients with coronary artery disease. Journal of Atherosclerosis and Thrombosis. 2015; 22: 447-454.

[210] Tousoulis D, Plastiras A, Siasos G, Oikonomou E, Verveniotis A, Kokkou E, et al. Omega-3 PUFAs improved endothelial func- tion and arterial stiffness with a parallel antiinflammatory effect in adults with metabolic syndrome. Atherosclerosis. 2014; 232: $10-16$.

[211] Yokoyama M, Origasa H, Matsuzaki M, Matsuzawa Y, Saito Y, Ishikawa Y, et al. Effects of eicosapentaenoic acid on major coronary events in hypercholesterolaemic patients (JELIS): a randomised open-label, blinded endpoint analysis. Lancet. 2007; 369: 1090-1098.

[212] Bhatt DL, Steg PG, Miller M, Brinton EA, Jacobson TA, Ketchum SB, et al. Cardiovascular Risk Reduction with Icosapent Ethyl for Hypertriglyceridemia. New England Journal of Medicine. 2019; 380: 11-22.

[213] Hjerkinn EM, Abdelnoor M, Breivik L, Bergengen L, Ellingsen I, Seljeflot I, et al. Effect of diet or very long chain ??-3 fatty acids on progression of atherosclerosis, evaluated by carotid plaques, intima???media thickness and by pulse wave propagation in elderly men with hypercholesterolaemia. European Journal of Cardiovascular Prevention \& Rehabilitation. 2006; 13: 325-333.

[214] Estruch R, Ros E, Martínez-González MA. Mediterranean diet for primary prevention of cardiovascular disease. The New England Journal of Medicine. 2013; 369: 676-677.

[215] King A. The benefits of a Mediterranean diet. Nature Reviews Cardiology. 2013; 10: 239-239.

[216] Giugliano D. Mediterranean Diet and Cardiovascular Health. Annals of the New York Academy of Sciences. 2005; 1056: 253-260.

[217] Shai I, Schwarzfuchs D, Henkin Y, Shahar DR, Witkow S, Greenberg I, et al. Weight Loss with a Low-Carbohydrate, Mediterranean, or Low-Fat Diet. New England Journal of Medicine. 2008; 359: 229-241.

[218] Martínez-González MA, Gea A, Ruiz-Canela M. The Mediterranean Diet and Cardiovascular Health: A critical review. Circulation Research. 2019; 124: 779-798.

[219] Tektonidis TG, Åkesson A, Gigante B, Wolk A, Larsson SC. A Mediterranean diet and risk of myocardial infarction, heart failure and stroke: a population-based cohort study. Atherosclerosis. 2015; 243: 93-98.

[220] Paterson KE, Myint PK, Jennings A, Bain LKM, Lentjes MAH, Khaw K, et al. Mediterranean Diet Reduces Risk of Incident Stroke in a Population with Varying Cardiovascular Disease Risk Profiles. Stroke. 2018; 49: 2415-2420.

[221] Bonaccio M, Di Castelnuovo A, Costanzo S, Persichillo M, De Curtis A, Donati MB, et al. Adherence to the traditional Mediterranean diet and mortality in subjects with diabetes. Prospective results from the MOLI-SANI study. European Journal of Preventive Cardiology. 2016; 23: 400-407.

[222] O’Connor LE, Hu EA, Steffen LM, Selvin E, Rebholz CM. Adherence to a Mediterranean-style eating pattern and risk of diabetes in a U.S. prospective cohort study. Nutrition \& Diabetes. 2020; 10: 8.

[223] Estruch R, Ros E, Salas-Salvadó J, Covas M, Corella D, Arós F, et al. Primary Prevention of Cardiovascular Disease with a Mediterranean Diet. New England Journal of Medicine. 2013; 368: $1279-1290$

[224] Liu S, Stampfer MJ, Hu FB, Giovannucci E, Rimm E, Manson $\mathrm{JE}$, et al. Whole-grain consumption and risk of coronary heart disease: results from the Nurses' Health Study. The American Journal of Clinical Nutrition. 1999; 70: 412-419.

[225] Soliman GA. Dietary fiber, atherosclerosis, and cardiovascular disease. Nutrients. 2019; 11: 1155.

[226] Anderson JW, Baird P, Davis Jr RH, Ferreri S, Knudtson M, Koraym A, et al. Health benefits of dietary fiber. Nutrition Reviews. 2009; 67: 188-205.

[227] Wu H, Dwyer KM, Fan Z, Shircore A, Fan J, Dwyer JH. Dietary fiber and progression of atherosclerosis: the Los Angeles Atherosclerosis Study. the American Journal of Clinical Nutrition. 2003; 78: 1085-1091.

[228] Expert Panel on Detection, Evaluation, and Treatment of High 
Blood Cholesterol in Adults. Executive Summary of the third Report of the National Cholesterol Education Program (NCEP) Expert Panel on Detection, Evaluation, and Treatment of High Blood Cholesterol in Adults (Adult Treatment Panel III). The Journal of the American Medical Association. 2001; 285: 24862497.

[229] Keene D, Price C, Shun-Shin MJ, Francis DP. Effect on cardiovascular risk of high density lipoprotein targeted drug treatments niacin, fibrates, and CETP inhibitors: meta-analysis of randomised controlled trials including 117411 patients. British Medical Journal. 2014; 349: g4379.

[230] Honarbakhsh S, Schachter M. Vitamins and cardiovascular disease. British Journal of Nutrition. 2008; 101: 1113-1131.

[231] Krishna SM. Vitamin D as a protector of arterial health: potential role in peripheral arterial disease formation. International Journal of Molecular Sciences. 2019; 20: 4907.

[232] Faridi KF, Zhao D, Martin SS, Lupton JR, Jones SR, Guallar E, et al. Serum vitamin $\mathrm{D}$ and change in lipid levels over $5 \mathrm{y}$ : the Atherosclerosis Risk in Communities study. Nutrition. 2017; 38: 85-93.

[233] Pilz S, Verheyen N, Grübler MR, Tomaschitz A, März W. Vitamin D and cardiovascular disease prevention. Nature Reviews Cardiology. 2016; 13: 404-417.

[234] Stojanovic OI, Lazovic M, Lazovic M, Vuceljic M. Association between atherosclerosis and osteoporosis, the role of vitamin $\mathrm{D}$. Archives of Medical Science. 2011; 7: 179-188.

[235] Xu Y, Arneja AS, Tappia PS, Dhalla NS. The potential health benefits of taurine in cardiovascular disease. Experimental and Clinical Cardiology. 2008; 13: 57-65.

[236] Peeke PM, Greenway FL, Billes SK, Zhang D, Fujioka K. Effect of time restricted eating on body weight and fasting glucose in participants with obesity: results of a randomized, controlled, virtual clinical trial. Nutrition \& Diabetes. 2021; 11: 6.

[237] Shereen MA, Khan S, Kazmi A, Bashir N, Siddique R. COVID-19 infection: Origin, transmission, and characteristics of human coronaviruses. Journal of Advanced Research. 2020; 24: 91-98.

[238] World Health Organization. WHO Coronavirus (COVID-19) Dashboard. 2021. Available at: https://covid19.who.int/ (Accessed: 1 May 2021).

[239] Suri JS, Agarwal S, Gupta SK, Puvvula A, Biswas M, Saba L, et al. A narrative review on characterization of acute respiratory distress syndrome in COVID-19-infected lungs using artificial intelligence. Computers in Biology and Medicine. 2021; 130: 104210 .

[240] Torres Acosta MA, Singer BD. Pathogenesis of COVID-19induced ARDS: implications for an ageing population. European Respiratory Journal. 2020; 56: 2002049.

[241] Cau R, Falaschi Z, Paschè A, Danna P, Arioli R, Arru CD, et al. CT findings of COVID-19 pneumonia in ICU-patients. Journal of Public Health Research. 2021. (in press).

[242] El-Baz A, Suri JS. Lung imaging and computer aided diagnosis. CRC Press: Florida, USA. 2011.

[243] Androutsos O, Perperidi M, Georgiou C, Chouliaras G. Lifestyle Changes and Determinants of Children's and Adolescents' Body Weight Increase during the First COVID-19 Lockdown in Greece: The COV-EAT Study. Nutrients. 2021; 13: 930.

[244] Spyropoulos AC, Weitz JI. Hospitalized COVID-19 Patients and Venous Thromboembolism: a perfect storm. Circulation. 2020; 142: 129-132.

[245] Brooks SK, Webster RK, Smith LE, Woodland L, Wessely S, Greenberg N, et al. The psychological impact of quarantine and how to reduce it: rapid review of the evidence. The Lancet. 2020; 395: 912-920.

[246] Ammar A, Trabelsi K, Brach M, Chtourou H, Boukhris O, Masmoudi L, et al. Effects of home confinement on mental health and lifestyle behaviours during the COVID-19 outbreak: insights from the ECLB-COVID19 multicentre study. Biology of
Sport. 2021; 38: 9.

[247] Blendon RJ, Benson JM, DesRoches CM, Raleigh E, TaylorClark K. The public's response to severe acute respiratory syndrome in Toronto and the United States. Clinical Infectious Diseases. 2004; 38: 925-931.

[248] Siti HN, Kamisah Y, Kamsiah J. The role of oxidative stress, antioxidants and vascular inflammation in cardiovascular disease (a review). Vascular Pharmacology. 2015; 71: 40-56.

[249] Butler MJ, Barrientos RM. The impact of nutrition on COVID19 susceptibility and long-term consequences. Brain, Behavior, and Immunity. 2020; 87: 53-54.

[250] Akseer N, Kandru G, Keats EC, Bhutta ZA. COVID-19 pandemic and mitigation strategies: implications for maternal and child health and nutrition. The American Journal of Clinical Nutrition. 2020; 112: 251-256.

[251] Aman F, Masood S. How Nutrition can help to fight against COVID-19 Pandemic. Pakistan Journal of Medical Sciences. 2020; 36: S121.

[252] Naja F, Hamadeh R. Nutrition amid the COVID-19 pandemic: a multi-level framework for action. European Journal of Clinical Nutrition. 2020; 74: 1117-1121.

[253] Brugliera L, Spina A, Castellazzi P, Cimino P, Arcuri P, Negro $\mathrm{A}$, et al. Nutritional management of COVID-19 patients in a rehabilitation unit. European Journal of Clinical Nutrition. 2020; 74: 860-863.

[254] Thibault R, Coëffier M, Joly F, Bohé J, Schneider SM, Déchelotte P. How the Covid-19 epidemic is challenging our practice in clinical nutrition-feedback from the field. European Journal of Clinical Nutrition. 2020; 75: 407-416.

[255] Calder PC. Nutrition, immunity and COVID-19. BMJ Nutrition, Prevention \& Health. 2020; 3: 74-92.

[256] Ferrara F, De Rosa F, Vitiello A. The Central Role of Clinical Nutrition in COVID-19 Patients during and after Hospitalization in Intensive Care Unit. SN Comprehensive Clinical Medicine. 2020; 2: 1064-1068.

[257] Zabetakis I, Lordan R, Norton C, Tsoupras A. COVID-19: the inflammation link and the role of nutrition in potential mitigation. Nutrients. 2020; 12: 1466.

[258] James PT, Ali Z, Armitage AE, Bonell A, Cerami C, Drakesmith $\mathrm{H}$, et al. Could nutrition modulate COVID-19 susceptibility and severity of disease? A systematic review. Journal of Nutrition. 2021; 151: 1854-1878.

[259] Silverio R, Gonçalves DC, Andrade MF, Seelaender M. Coronavirus Disease 2019 (COVID-19) and Nutritional Status: the Missing Link? Advances in Nutrition. 2020; 12: 682-692.

[260] Hussain A, Mahawar K, Xia Z, Yang W, El-Hasani S. Obesity and mortality of COVID-19. Meta-analysis. Obesity Research \& Clinical Practice. 2020; 14: 295-300.

[261] Korakas E, Ikonomidis I, Kousathana F, Balampanis K, Kountouri A, Raptis A, et al. Obesity and COVID-19: immune and metabolic derangement as a possible link to adverse clinical outcomes. American Journal of Physiology-Endocrinology and Metabolism. 2020; 319: E105-E109.

[262] Kwok S, Adam S, Ho JH, Iqbal Z, Turkington P, Razvi S, et al. Obesity: A critical risk factor in the COVID 19 pandemic. Clinical Obesity. 2020; 10: e12403.

[263] Nakeshbandi M, Maini R, Daniel P, Rosengarten S, Parmar P, Wilson C, et al. The impact of obesity on COVID-19 complications: a retrospective cohort study. International Journal of Obesity. 2020; 44: 1832-1837.

[264] Popkin BM, Du S, Green WD, Beck MA, Algaith T, Herbst $\mathrm{CH}$, et al. Individuals with obesity and COVID 19: a global perspective on the epidemiology and biological relationships. Obesity Reviews. 2020; 21: e13128.

[265] Yang J, Hu J, Zhu C. Obesity aggravates COVID 19: a systematic review and meta analysis. Journal of Medical Virology. 2021; 93: 257-261.

[266] Sattar Y, Ullah W, Rauf H, Virk HUH, Yadav S, Chowdhury M, et al. COVID-19 cardiovascular epidemiology, cellular patho- 
genesis, clinical manifestations and management. IJC Heart \& Vasculature. 2020; 29: 100589.

[267] Saba L, Gerosa C, Fanni D, Marongiu F, La Nasa G, Caocci G, et al. Molecular pathways triggered by COVID-19 in different organs: ACE2 receptor-expressing cells under attack? A review. European Review for Medical and Pharmacological Sciences. 2020; 24: 12609-12622.

[268] Saba L, Gerosa C, Wintermark M, Hedin U, Fanni D, Suri JS, et al. Can COVID19 trigger the plaque vulnerability—a Kounis syndrome warning for "asymptomatic subjects". Cardiovascular Diagnosis and Therapy. 2020; 10: 1352-1355.

[269] Potempa LA, Rajab IM, Hart PC, Bordon J, Fernandez-Botran R. Insights into the Use of C-Reactive Protein as a Diagnostic Index of Disease Severity in COVID-19 Infections. The American Journal of Tropical Medicine and Hygiene. 2020; 103: 561-563.

[270] Wang L. C-reactive protein levels in the early stage of COVID19. MéDecine Et Maladies Infectieuses. 2020; 50: 332-334.

[271] Nishiga M, Wang DW, Han Y, Lewis DB, Wu JC. COVID-19 and cardiovascular disease: from basic mechanisms to clinical perspectives. Nature Reviews Cardiology. 2020; 17: 543-558.

[272] Szeto C, Sugano K, Wang J, Fujimoto K, Whittle S, Modi GK, et al. Non-steroidal anti-inflammatory drug (NSAID) therapy in patients with hypertension, cardiovascular, renal or gastrointestinal comorbidities: joint APAGE/APLAR/APSDE/APSH/APSN/PoA recommendations. Gut. 2020; 69: 617-629.

[273] Liu D, Zeng X, Ding Z, Lv F, Mehta JL, Wang X. Adverse Cardiovascular Effects of Anti-COVID-19 Drugs. Frontiers in Pharmacology. 2021; 12: 699949.

[274] Qiao W, Wang C, Chen B, Zhang F, Liu Y, Lu Q, et al. Ibuprofen attenuates cardiac fibrosis in streptozotocin-induced diabetic rats. Cardiology. 2015; 131: 97-106.

[275] Cau R, Pacielli A, Fatemeh H, Vaudano P, Arru C, Crivelli P, et al. Complications in COVID-19 patients: Characteristics of pulmonary embolism. Clinical Imaging. 2021; 77: 244-249.

[276] Badimon L, Vilahur G, Padro T. Nutraceuticals and atherosclerosis: human trials. Cardiovascular Therapeutics. 2010; 28 : 202-215.

[277] Bolla K, KV SS. Diet during Cardiovascular Diseases. Journal of Medicine, Physiology and Biophysics. 2016; 23: 24-31.

[278] Tarkin JM, Dweck MR, Evans NR, Takx RAP, Brown AJ, Tawakol A, et al. Imaging Atherosclerosis. Circulation Research. 2016; 118: 750-769.

[279] Casas R, Castro-Barquero S, Estruch R, Sacanella E. Nutrition and cardiovascular health. International Journal of Molecular Sciences. 2018; 19: 3988

[280] Biswas M, Kuppili V, Saba L, Edla DR, Suri HS, CuadradoGodia E, et al. State-of-the-art review on deep learning in medical imaging. Frontiers in Bioscience-Landmark. 2019; 24: 392426.
Appendix See Figs. 13,14.

Abbreviations: SN, Acronym, Description; ACC, American College of Cardiology; AE, AtheroEdge ${ }^{\mathrm{TM}}$, Roseville, CA, USA; AHA, American Heart Association; ApoB100, Apolipoprotein B; ApoC-III, Apolipoprotein C-III; ASCVD, Atherosclerotic Cardiovascular Disease; BMI, Body Mass Index; BMUS, B-mode Ultrasound; CCVRC, Conventional Cardiovascular Risk Calculator; CHD, Coronary Heart Disease; CIMT, Carotid Intima-Media Thickness; CKD, Chronic Kidney Disease; CTA, Computed Tomography Angiography; CVD, Cardiovascular Diseases; CVE, Cardiovascular Events; DHA, Docosahexanoic acid; DQI, Diet Quality Index; EC, Endothelial cells; eGFR, Estimated Glomerular Filtration Rate; EPA, Eicosapentaenoic acid; ESR, Erythrocyte Sedimentation Rate; FMO, Flavin Monoxygenase; FRS, Framingham Risk Score; HbA1c, Haemoglobin A1c; hCRP, C-reactive protein; HDL, High-Density Lipoprotein; ICA, Internal Carotid Artery; IDL, Intermediate Density Lipoprotein; IL-17, Interleukin 17; IL-6, Interleukin 6; JELIS, Japan EPA Lipid Intervention Study; LDL, Low-Density Lipoprotein; mCRP, Monomeric C-reactive protein; MRI, Magnetic Resonance Imaging; OCT, Optical Coherence Tomography; PCRE, Pooled Cohort Risk Equation; PET, Positron Emission Tomography; PUFA, Poly Unsaturated Fatty Acid; RA, Rheumatoid Arthritis; SC, Smooth Cells; TG, Triglycerides; TGF- $\beta$, Transforming growth factor-beta; TMA, Trimethylamine; TMAO, Trimethylamine N-oxide levels; TNF- $\alpha$, Tumour Necrosis Factor-alpha; VLDL, Very Low-Density Lipoprotein; WHO, World Health Organisation.

Keywords: Nutrition; Atherosclerosis; CVD; Arterial imaging; Carotid; Ultrasound; Artificial intelligence; Risk stratification; Treatment; COVID-19; Plaque tissue characterization

Send correspondence to: Jasjit S. Suri, Stroke Monitoring and Diagnostic Division, AtheroPoint ${ }^{\mathrm{TM}}$, Roseville, CA 95678, USA, E-mail: jasjit.suri@atheropoint.com 


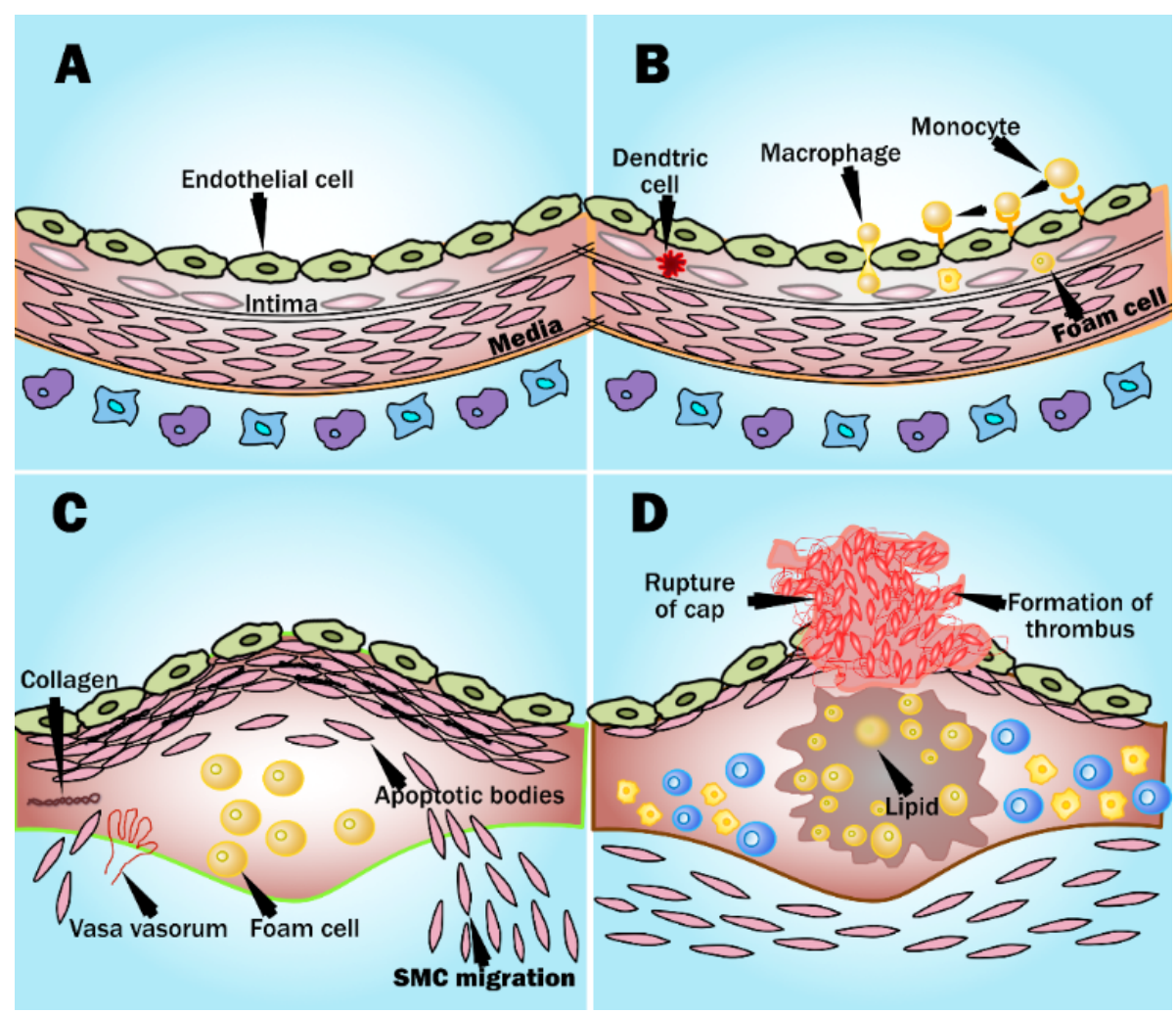

Fig. 13. Atheroma development and plaque rupture (courtesy of AtheroPoint, Roseville, CA, USA). (A) Healthy blood vessel with no change in the geometry of the endothelial layer. (B) Penetration of monocytes in the intimal layer. (C) Formation of plaque with foam cells and migration of smooth muscle cells. (D) Atherosclerotic plaque rupture and formation of thrombus.

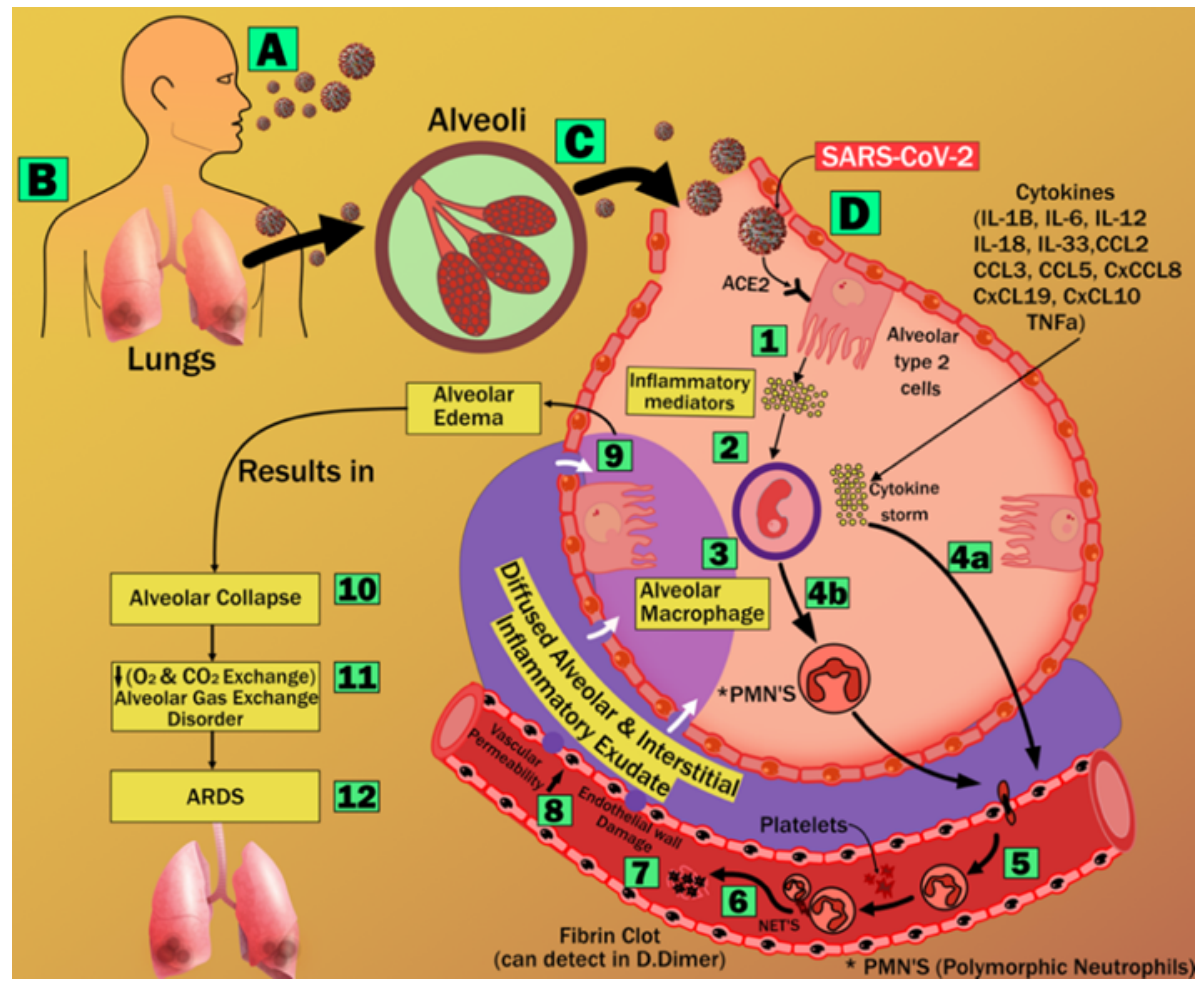

Fig. 14. Acute Respiratory Distress Syndrome (ARDS) due to COVID-19 (courtesy of AtheroPoint, Roseville, CA, USA). 